Supporting Information for

\title{
Conjugated BODIPY Oligomers with Controllable Near-Infrared Absorptions as Promising Phototheranostic Agents through Excited-State Intramolecular Rotations
}

Qinghua Wu, ${ }^{\dagger[\mathrm{a}]}$ Yucheng Zhu, ${ }^{\dagger[\mathrm{b}]}$ Xingbao Fang, ${ }^{[\mathrm{a}]}$ Xiangyu Hao, ${ }^{[\mathrm{a}]}$ Lijuan Jiao, ${ }^{*[\mathrm{a}]}$ Erhong Hao, ${ }^{*[a]}$ Weian Zhang, ${ }^{[b]}$

${ }^{a}$ Laboratory of Functionalized Molecular Solids, Ministry of Education, College of Chemistry and Material Science, Anhui Normal University, Wuhu, 241002, China.

b Shanghai Key Laboratory of Functional Materials Chemistry, School of Chemistry and Molecular Engineering, East China University of Science and Technology, Shanghai, 200237, China.

$\dagger$ these authors contributed equally.

*To whom correspondence: jiao421@ahnu.edu.cn; haoehong@ahnu.edu.cn; wazhang@ecust.edu.cn.

\section{Contents}

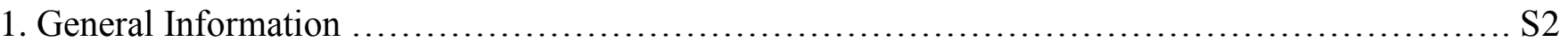

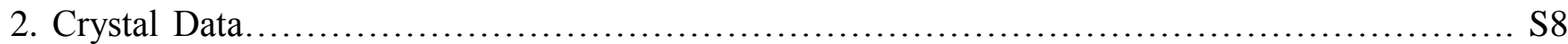

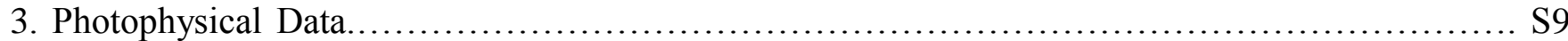

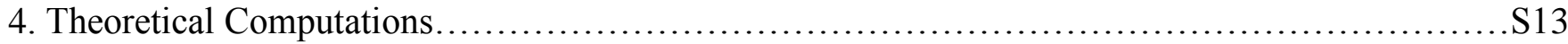

5. Characterization and Properties of Nanoparticles.............................................. S17

7. Targeted Multifunctional Imaging Properties of Nanoparticles..................................S22

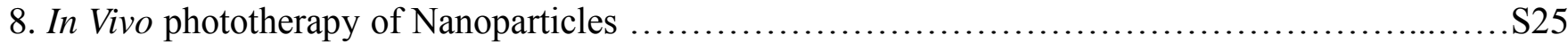

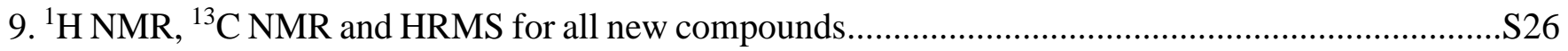




\section{General Information}

Materials and Instruments. Reagents and solvents were used as received from commercial suppliers (Energy Chemicals, Shanghai, China) unless noted otherwise. All reactions were performed in oven-dried or flame-dried glassware unless stated otherwise and were monitored by TLC using $0.25 \mathrm{~mm}$ silica gel plates with UV indicator (60F-254). ${ }^{1} \mathrm{H}$ and ${ }^{13} \mathrm{C}$ NMR spectra were recorded on Bruker ARX 400 or 500 $\mathrm{MHz}$ NMR spectrometer at room temperature. Chemical shifts $(\delta)$ are given in ppm relative to $\mathrm{CDCl}_{3}$ (7.26 ppm for ${ }^{1} \mathrm{H}$ and $77 \mathrm{ppm}$ for ${ }^{13} \mathrm{C}$ ) or to internal TMS. High-resolution mass spectra (HRMS) were a Finnigan MAT TSQ 7000 mass spectrometer system operating in MALDI-TOF mode.

UV-visible absorption and fluorescence emission spectra were recorded on commercial spectrophotometers (Shimadzu UV-4100 and Edinburgh FS5 or FLS 1000 spectrometers). All measurements were made at $25{ }^{\circ} \mathrm{C}$, using $10 \times 10 \mathrm{~mm}$ cuvettes. Relative fluorescence quantum efficiencies of BODIPY derivatives were obtained by comparing the areas under the corrected emission spectrum of the test sample in various solvents with 1,7-diphenyl-3,5- $\operatorname{di}(p$-methoxyphenyl)azadipyrromethene $(\phi=0.36 \text { in chloroform })^{1}$ and $\operatorname{ECXb}\left(\phi=0.14 \text { in } \mathrm{CH}_{2} \mathrm{Cl}_{2}\right)^{2}$ as the reference. Nondegassed, spectroscopic grade solvents and a $10 \mathrm{~mm}$ quartz cuvette were used. Dilute solutions $(0.01<\mathrm{A}<0.05)$ were used to minimize the reabsorption effects. Quantum yields were determined using the following equation $(1):^{3}$

$$
\Phi_{x}=\Phi_{r} \times \frac{F_{x}}{F_{r}} \times \frac{1-10^{-A_{r}\left(\lambda_{\mathrm{ex}}\right)}}{1-10^{-A_{x}\left(\lambda_{\mathrm{ex}}\right)}} \times \frac{n_{x}^{2}}{n_{r}^{2}}
$$

where the subscripts $x$ and $r$ refer respectively to the BODIPY sample $x$ and reference (standard) fluorophore $r$ with known quantum yield $\Phi_{r}$ in a specific solvent; $F$ stands for the spectrally corrected, integrated fluorescence spectra; $A\left(\lambda_{\text {ex }}\right)$ denotes the absorbance at the used excitation wavelength $\lambda_{\text {ex }}$ and $n$ represents the refractive index of the solvent (in principle at the average emission wavelength).

Crystals of compounds $\mathbf{2} \mathbf{C l}_{\mathbf{2}}$ suitable for X-ray analysis was obtained via the slow diffusion of petroleum ether into their dichloromethane solutions. The vial containing this solution was placed, loosely capped, to promote the crystallization. A suitable crystal was chosen and mounted on a glass fiber using grease. Data were collected using a diffractometer equipped with a graphite crystal monochromator situated in the incident beam for data collection at room temperature. Cell parameters were retrieved using SMART $^{4}$ software and refined using SAINT on all observed reflections. The determination of unit cell 
parameters and data collections were performed with Mo $K \alpha$ radiation $(\lambda)$ at $0.71073 \AA$. Data reduction was performed using the SAINT software, ${ }^{5}$ which corrects for Lp and decay. The structure was solved by the direct method using the SHELXS- $97^{6}$ program and refined by least squares method on $F^{2}$, SHELXL2018/3, incorporated in SHELXTL V5.10. ${ }^{7}$ CCDC-1991864 (2Cl 2$)$ contain the supplementary crystallographic data for this paper. These data can be obtained free of charge from The Cambridge Crystallographic Data Centre via www.ccdc.cam.ac.uk/data_request/cif.

The polydispersity index $(\mathrm{Mw} / \mathrm{Mn})$ and the number average weight $(\mathrm{Mn})$ were measured by a Waters 1515 gel permeation chromatograph (GPC) equipped with ultrastyragel columns of 100-10000 porosities and refractive index detector. THF was used as the eluent at a flow rate of $1 \mathrm{~mL} \mathrm{~min}^{-1}$ and polystyrene was used as the standard to calibrate the GPC system.

Transmission electron microscopy (TEM) was performed on a JEOL JEM1400 electron microscope operated at $100 \mathrm{kV}$. The sample for TEM was prepared by directly dropping the self-assembled aqueous solution $\left(0.2 \mathrm{mg} \mathrm{mL}^{-1}\right)$ onto a carbon-coated copper grid, and the sample was measured until the solution dried at ambient temperature. Hydrodynamic diameter $\left(D_{h}\right)$ was measured by dynamic light scattering (DLS) using a BECKMAN COULTER Delasa Nano C particle analyzer with the wavelength of $532 \mathrm{~nm}$ at $25^{\circ} \mathrm{C}$ and the scattering angle was $165^{\circ}$.

Self-assembly of Nanoparticles. As a typical nanoprecipitation method, PEG5000- $\boldsymbol{b}$-PDPA22 (15 mg) and $\mathbf{2}(1 \mathrm{mg})$ was first dissolved in $1 \mathrm{~mL}$ THF and then the $\mathbf{2}$ solution was added dropwise into $4 \mathrm{~mL}$ of distilled water under magnetic stirring at ambient temperature in $0.5 \mathrm{~h}$. The mixture solution was stirred for $3 \mathrm{~h}$ and dialyzed against distilled water using a dialysis membrane $(\mathrm{MWCO}=3500)$ for 3 days to give 2-NPs.

The same methods were used to give 3 -NPs and 4-NPs.

In Vitro Drug Release profile. To reveal the drug release profile, $5 \mathrm{~mL}$ of PBS solution with various $\mathrm{pH}$ values (7.4 or 6.5) containing drug-loaded nanoparticles (2-NPs, 3-NPs or 4-NPs) was put into a dialysis bag $(\mathrm{MWCO}=3500)$ and the bag was then immersed in $50 \mathrm{~mL}$ of PBS contained Tween-80 (1\%) and stirred at $37{ }^{\circ} \mathrm{C}$. One milliliter of solution outside the dialysis bag was withdrawn at appointed time points and supplemented with fresh buffer. The cumulative drug release curves were assessed based on the absorbance of $\mathbf{2}, \mathbf{3}$ or 4 .

Singlet Oxygen Detection. The singlet oxygen $\left({ }^{1} \mathrm{O}_{2}\right)$ generation yield of 2, 3, 4, 2-NPs, 3-NPs, 4-NPs were evaluated by singlet oxygen capture agent, 1,3-diphenlisobenzofuran (DPBF). Briefly, the 
absorbance of DPBF at $415 \mathrm{~nm}$ was adjusted to about 1.0 in DMF, and 2 was added to cuvette. The cuvette was then exposed to a $660 \mathrm{~nm}$ laser for different time, and the corresponding absorption spectra was measured immediately. The slopes of absorbance of DPBF at $415 \mathrm{~nm}$ versus irradiation time were measured and used to compare the ${ }^{1} \mathrm{O}_{2}$ generation ability. For 2-NPs mediated ${ }^{1} \mathrm{O}_{2}$ production, the procedure was similar with that of $\mathbf{2}$. For $\mathbf{3}$ and $\mathbf{3}$-NPs solution, the cuvettes were irradiated by $808 \mathrm{~nm}$ laser and the procedures were similar with that of $\mathbf{2}$. For $\mathbf{4}$ and $\mathbf{4}$-NPs, the solutions were irradiated by a $980 \mathrm{~nm}$ laser and the other procedures were similar with that of $\mathbf{2}$.

Photothermal Effect. To demonstrate the photothermal conversion behavior of 2-NPs, 3-NPs and 4-NPs, the solutions containing 2-NPs, 3-NPs and 4-NPs at the concentrations of 0, 20.0 and $50.0 \mu \mathrm{g} / \mathrm{mL}$ were irradiated for $300 \mathrm{~s}$ in $0.2 \mathrm{~mL}$ glass vials under $660 \mathrm{~nm}, 808 \mathrm{~nm}$ or $980 \mathrm{~nm}$ light, respectively. Moreover, 2-NPs and 4-NPs at the concentration of $50 \mu \mathrm{g} / \mathrm{mL}$ were irradiated by using a $660 \mathrm{~nm}$ laser at $0.3,0.5$ and $1 \mathrm{~W} \mathrm{~cm}^{-2}$ for $300 \mathrm{~s}, 3-\mathrm{NPs}$ at the concentration of $50 \mu \mathrm{g} / \mathrm{mL}$ were irradiated by using a $808 \mathrm{~nm}$ laser at 0.1 , 0.25 and $0.5 \mathrm{~W} \mathrm{~cm}^{-2}$ for $300 \mathrm{~s}$. To demonstrate the photothermal conversion efficiency, the solutions of 2 NPs, 3-NPs and 4-NPs at the concentration of $50.0 \mu \mathrm{g} \mathrm{mL}^{-1}$ in quartz cuvettes were irradiated under 660, 808 or $980 \mathrm{~nm}$ light at $1,0.25$ or $0.5 \mathrm{~W} \mathrm{~cm}^{-2}$. When the temperature reached a plateau, the irradiation was removed for cooling down to room temperature. The temperature of the solution was recorded at an interval of $10 \mathrm{~s}$ during the whole experiment, and then the photothermal conversion efficiencies were calculated.

To evaluate the photostability, 2, MB, 3, ICG and 4 in DMF were irradiated by $660 \mathrm{~nm}, 808 \mathrm{~nm}$ or $980 \mathrm{~nm}$ light exposure at $1 \mathrm{~W} \mathrm{~cm}^{-2}$ for $5,10,15,20,25$ and $30 \mathrm{~min}$, respectively, followed by the measurements of their concentrations. Then, their UV-vis absorption spectra were measured.

Cell Cultures. 4T1 cells were cultured in Dulbecco's modified Eagle's medium (DMEM) comprised of antibiotics (50 units $\mathrm{mL}^{-1}$ penicillin and 50 units $\mathrm{mL}^{-1}$ streptomycin) and $10 \%$ fetal bovine serum (FBS) at $37{ }^{\circ} \mathrm{C}$ in a humidified atmosphere with $5 \% \mathrm{CO}_{2}$.

In vitro Dark Cytotoxicity and Phototoxicity. For in vitro phototoxicity, 4T1 cells (25000 cells $\mathrm{mL}^{-1}$, $200 \mu \mathrm{L}$ ) was seeded into a 96-well plate and cultured for $24 \mathrm{~h}$ at $37^{\circ} \mathrm{C}$. The culture medium was replaced with a fresh culture medium containing 2-NPs, 3-NPs and 4-NPs (where the BDP concentration was at 0$45 \mu \mathrm{g} \mathrm{mL}{ }^{-1}$, respectively). After the cells were incubated for $24 \mathrm{~h}$ at $37^{\circ} \mathrm{C}$, they were irradiated using a $660 \mathrm{~nm}, 808 \mathrm{~nm}$ or $980 \mathrm{~nm}$ laser $\left(250 \mathrm{~mW} \mathrm{~cm}^{-2}\right)$ for $10 \mathrm{~min}$, respectively. After irradiation, these tumor cells were incubated for another $24 \mathrm{~h}$. Thereafter, the culture medium was replaced with a fresh culture 
medium and $20 \mu \mathrm{L}$ MTT ( $5 \mathrm{mg} \mathrm{mL}^{-1}$ ) for a further incubation of $4 \mathrm{~h}$. Finally, the culture medium containing MTT was replaced with $150 \mu \mathrm{L}$ DMSO to dissolve the precipitates, followed by measuring the absorbance of solution at $492 \mathrm{~nm}$ by THERMO Multiskan MK3 spectrometer, a spectrophotometric microplate reader. Cell viability was calculated by the Eqn (2):

$$
\text { Cell viability }(\%)=\left(O D_{\mathrm{t}}-\mathrm{OD}_{\mathrm{b}}\right) /\left(\mathrm{OD}_{\mathrm{c}}-\mathrm{OD}_{\mathrm{b}}\right) \times 100
$$

where $\mathrm{OD}_{\mathrm{b}}$ is the absorbance of the background; $\mathrm{OD}_{\mathrm{t}}$ and $\mathrm{OD}_{\mathrm{c}}$ are the absorbance of solutions with or without samples, respectively.

For in vitro dark cytotoxicity, the process was similar to the phototoxicity described above, but without the irradiation.

Cellular Uptake Studies. The cellular uptake experiments were carried out by confocal laser scanning microscope (CLSM). For CLSM measurement, 4T1 cells were cultured in $2 \mathrm{~mL}$ culture medium on polylysine-coated glass slides inside $30 \mathrm{~mm}$ glass culture dishes and allowed to grow to $50-70 \%$ at $37{ }^{\circ} \mathrm{C}$. Afterward, cells (on glass slides) were washed with PBS, and reincubated in DMEM medium containing the samples at $37{ }^{\circ} \mathrm{C}$ under $5 \% \mathrm{CO}_{2}$ for $24 \mathrm{~h}$. Then, the cells were treated with 2-NPs in DMEM in concentration of $8 \mu \mathrm{g} / \mathrm{mL}$ and treated for $2 \mathrm{~h}$ and $8 \mathrm{~h}$. After predetermined time, the culture medium was removed and washed with PBS three times. Subsequently, the 4, 6-diamidino-2-phenylindole (DAPI) (1 $\mu \mathrm{g} / \mathrm{mL}$ ) was added to stain the nuclei for $30 \mathrm{~min}$. Then the cells were imaged directly via CLSM after washing with PBS three times.

Intracellular ROS Detection. Intracellular ROS production was measured via 2',7'dichlorodihydrofluorescein diacetate (DCFH-DA) using CLSM and flow cytometry, respectively. When taken up by cells, DCFH-DA will be deacetylated by the intracellular esterases to form dichlorodihydrofluorescein (DCFH). DCFH can transfer to fluorescent dichlorofluorescein (DCF) in the presence of ROS. 4T1 cells were plated onto glass bottom petri dishes with $1 \times 10^{5}$ cells per well. After $24 \mathrm{~h}$ incubation, the cells were treated with 2-NPs, 3-NPs and 4-NPs with the same concentration $(8 \mu \mathrm{g} / \mathrm{mL})$ for $8 \mathrm{~h}$, respectively. After washed with PBS to remove the residual nanomaterials, the cells were incubated with DCFH-DA $(10 \mu \mathrm{g} / \mathrm{mL})$ for $30 \mathrm{~min}$. After that the cells were thoroughly washed with PBS then irradiated with $660 \mathrm{~nm}$ laser $\left(1 \mathrm{~W} \mathrm{~cm}^{-2}, 10 \mathrm{~min}\right), 808 \mathrm{~nm}$ laser ( $\left.1 \mathrm{~W} \mathrm{~cm}^{-2}, 10 \mathrm{~min}\right), 980 \mathrm{~nm}$ laser (1 $\left.\mathrm{W} \mathrm{cm}{ }^{-2}, 10 \mathrm{~min}\right)$, respectively. Finally, the fluorescence of DCF was observed by CLSM for each group. 
Animals and Tumor Models. All animal experiments were approved by the regional animal committee and were in accordance with international guidelines on the ethical use of laboratory animals. Female $\mathrm{BALB} / \mathrm{c}$ nude mice (4 to 6-week-old) were maintained in a pathogen free environment under controlled temperature $\left(24^{\circ} \mathrm{C}\right)$. The female nude mice were subcutaneously injected in the right leg region with 100 $\mu \mathrm{L}$ of cell suspension containing $5 \times 10^{6} 4 \mathrm{~T} 1$ cells. The tumors were allowed to grow to $\sim 100 \mathrm{~mm}^{3}$ before experimentation. The tumor volume was calculated as (tumor length) $\times(\text { tumor width })^{2} / 2$.

In Vitro and In Vivo PA Imaging. The PA imaging was performed with a multispectral optoacoustic tomography scanner (MSOT, iThera medical, inVision 128, Germany), which was equipped with an array of 128 cylindrically focused transducers to detect PA signals and a tunable pulsed laser (680-980 nm, 10 $\mathrm{Hz}$ repetition rate) to generate the PA effect. Polypropylene and tygon tubes put across the center of a water bath were tested. The PA spectrum between 750 and $950 \mathrm{~nm}$ was measured with an average laser energy density of $20 \mathrm{~mJ} \mathrm{~cm}{ }^{-2}$. The PA property of 2-NPs, 3-NPs and 4-NPs in aqueous solutions with different concentrations $\left(20,50 \mu \mathrm{g} \mathrm{mL}^{-1}\right)$ was excited by 750,808 and $950 \mathrm{~nm}$, respectively. The intensity was calculated by region of interest analysis on the MSOT imaging system. The PA images were reconstructed using the coherence factor-based sound speed correction method.

After the tumors reached about $100 \mathrm{~mm}^{3}$, 2-NPs, 3-NPs and 4-NPs $\left(0.5 \mathrm{mg} \mathrm{kg}^{-1}\right.$ of body weight) were intravenously injected into the 4T1 tumor-bearing mice in the right hind leg with a dose of $0.5 \mathrm{mg} \mathrm{kg}^{-1}$ body weight. Followed by anesthetization with isoflurane, mice were placed in a water bath to maintain their body temperature at $37{ }^{\circ} \mathrm{C}$ for PA imaging. PA images were acquired at different time-points postinjection by a multispectral PA tomography instrument with an excitation wavelength of $680 \mathrm{~nm}$. Ten slices were obtained at each position and averaged to increase of the ratio of signal to noise. The field of view was $25 \times 25 \mathrm{~mm}^{2}$.

In vivo Tissue Distributions Study. $4 \mathrm{~T} 1$ tumor model was established by subcutaneous injection of 4T1 cells $(1 * 105)$ on the right back of hind leg positions of the Balb/c-nu mice (4-5 weeks old). The tissue distribution study started when tumors reached a size $150-200 \mathrm{~mm}^{3}$. 4T1 tumor bearing mice were intravenously injected with $150 \mu \mathrm{L}$ of 2-NPs $(50 \mu \mathrm{g} / \mathrm{mL})$. The biodistribution of mice were detected by exciting samples at $660 \mathrm{~nm}$ with an in vivo small animal imaging system. At $8 \mathrm{~h}$ after the injection, mice were euthanized and their tumors and normal tissue including heart, liver, spleen, lung, and kidney were collected and detected. 
In Vivo Photothermal Imaging. When the tumors grew to $100 \mathrm{~mm}^{3}$, mice were intratumorally injected with $125 \mu \mathrm{L}$ of 2-NPs (50 $\mu \mathrm{g} / \mathrm{mL}), 3-\mathrm{NPs}(50 \mu \mathrm{g} / \mathrm{mL}), 4-\mathrm{NPs}(50 \mu \mathrm{g} / \mathrm{mL})$, respectively. Then, the tumors suffered from $660 \mathrm{~nm}, 808 \mathrm{~nm}$ or $980 \mathrm{~nm}$ light exposure at $1 \mathrm{~W} \mathrm{~cm}^{-2}$ for $5 \mathrm{~min}$. The temperature variation of the tumor site was recorded by an IR thermal camera at different time intervals.

In Vivo Phototherapy. When the tumor volume reached about $100 \mathrm{~mm}^{3}$, tumor-bearing mice were divided into seven groups ( $n=5$ mice/group) randomly for different formulations: (1) saline alone; (2) 2 NPs; (3) 3-NPs; (4) 4-NPs; (5) 2-NPs + $660 \mathrm{~L}$; (6) 3-NPs + $808 \mathrm{~L}$ and (7) 4-NPs + $980 \mathrm{~L}$. The solution of different groups $\left(125 \mu \mathrm{L}, 1 \mathrm{mg} \mathrm{mL}^{-1}\right)$ was intratumorally injected into mice. Then, the tumors suffered from $660 \mathrm{~nm}, 808 \mathrm{~nm}$ or $980 \mathrm{~nm}$ light exposure at $0.5 \mathrm{~W} \mathrm{~cm}^{-2}$ for $10 \mathrm{~min}$, respectively. The tumor dimensions (length and width) and body weight were measured every two days after the treatment. The mice were sacrificed after 2 weeks post-treatment, the tumors were collected, and photos were taken.

Tissue Immunohistological Evaluation. In the histological assay, the heart, liver, spleen, lung, kidney and tumor tissues were fixed in $4 \%$ paraformaldehyde for $24 \mathrm{~h}$. The specimens were dehydrated in graded ethanol, embedded in paraffin, and cut into $5 \mathrm{~mm}$ thick sections. The fixed sections were deparaffinized and hydrated according to a standard protocol and stained with hematoxylin and eosin (H\&E) for microscopic observation. Apoptosis of the tumor cells in the mice after treatments was determined by the TUNEL method according to the manufacturer's instructions.

DFT Calculation. The ground state geometry was optimized by using DFT method at B3LYP/6-31G(d) level. The same method was used for vibrational analysis to verify that the optimized structures correspond to local minima on the energy surface. TD-DFT computations were used the optimized ground state geometries under the B3LYP/6-31+G $(\mathrm{d}, \mathrm{p})$ theoretical level. The calculated molecules in dichloromethane were done using the Self-Consistent Reaction Field (SCRF) method and Polarizable Con-tinuum Model (PCM). The geometries of the lowest singlet (S1) excited states were also optimized at the TD-B3LYP/6$31 \mathrm{G}(\mathrm{d})$ level of theory. In addition, the S0 and S1 potential energy curves were qualitatively scanned by constrained optimizations, keeping the dihedral angels fixed at a series of values. All of the calculations were carried out by the methods implemented in Gaussian 09 package. ${ }^{8 a}$ SOCs were computed using the quadratic-response TDDFT approach, ${ }^{8 b}$ i.e. QR-TD-DFT, as implemented in the Dalton program ${ }^{8 \mathrm{c}}$ at their S1 optimized geometries. The SOC operator makes use of a semi-empirical effective single-electron approximation. ${ }^{8 \mathrm{~d}}$ For the latter calculations the B3LYP functional in combination to the $6-31 \mathrm{G}(\mathrm{d})$ basis set was used. 


\section{Crystal Data}

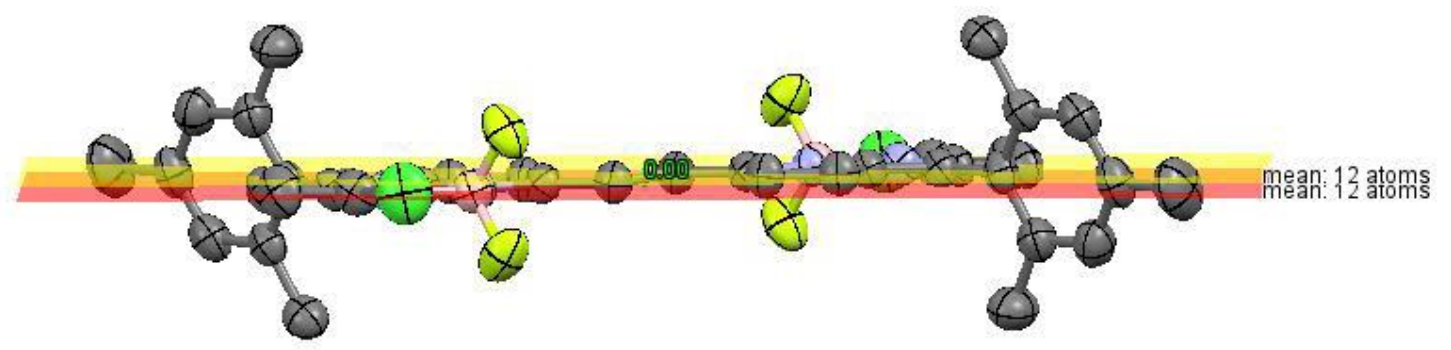

Figure S1. The dihedral angle between the two BODIPY units.

Table S1. Crystal data and structure refinement for $\mathbf{2} \mathbf{C l}_{2}$.

\begin{tabular}{|c|c|}
\hline Identification code & $2 \mathrm{Cl}_{2}$ \\
\hline Empirical formula & $\mathrm{C}_{38} \mathrm{H}_{32} \mathrm{~B}_{2} \mathrm{Cl}_{2} \mathrm{~F}_{4} \mathrm{~N}_{4}$ \\
\hline Formula weight & 713.19 \\
\hline Temperature/K & 273.15 \\
\hline Crystal system & monoclinic \\
\hline Space group & $\mathrm{P} 2{ }_{1} / \mathrm{c}$ \\
\hline $\mathrm{a} / \AA$ & $9.9434(8)$ \\
\hline $\mathrm{b} / \AA$ & $20.0627(15)$ \\
\hline $\mathrm{c} / \AA$ & $11.3209(10)$ \\
\hline$\alpha /^{\circ}$ & 90 \\
\hline$\beta /^{\circ}$ & $107.969(3)$ \\
\hline$\gamma /{ }^{\circ}$ & 90 \\
\hline Volume $/ \AA^{3}$ & $2148.3(3)$ \\
\hline $\mathrm{Z}$ & 2 \\
\hline$\rho_{\text {calc }} \mathrm{g} / \mathrm{cm}^{3}$ & 1.103 \\
\hline$\mu / \mathrm{mm}^{-1}$ & 0.196 \\
\hline $\mathrm{F}(000)$ & 736.0 \\
\hline Crystal size $/ \mathrm{mm}^{3}$ & $0.21 \times 0.2 \times 0.2$ \\
\hline Radiation & $\operatorname{MoK} \alpha(\lambda=0.71073)$ \\
\hline $2 \Theta$ range for data collection ${ }^{\circ}$ & 5.92 to 55.136 \\
\hline Index ranges & $-12 \leq \mathrm{h} \leq 12,-26 \leq \mathrm{k} \leq 26,-14 \leq 1 \leq 14$ \\
\hline Reflections collected & 83433 \\
\hline Independent reflections & $4944\left[\mathrm{R}_{\text {int }}=0.0409, \mathrm{R}_{\text {sigma }}=0.0155\right]$ \\
\hline Data/restraints/parameters & $4944 / 0 / 229$ \\
\hline Goodness-of-fit on $\mathrm{F}^{2}$ & 1.069 \\
\hline Final $\mathrm{R}$ indexes $[\mathrm{I}>=2 \sigma(\mathrm{I})]$ & $\mathrm{R}_{1}=0.0601, \mathrm{wR}_{2}=0.1663$ \\
\hline Final $\mathrm{R}$ indexes [all data] & $\mathrm{R}_{1}=0.0800, \mathrm{wR}_{2}=0.1850$ \\
\hline Largest diff. peak/hole / e $\AA^{-3}$ & $0.27 /-0.46$ \\
\hline
\end{tabular}




\section{Photophysical Data}

Table S2. Photophysical properties of $\mathbf{2 , 3}$ and $\mathbf{4}$ in different solvents at room temperature.

\begin{tabular}{ccccccc}
\hline dyes & solvent & $\lambda_{\max (\mathrm{nm})}$ & $\left.\lambda_{\text {em }(\mathrm{nm})}\right)^{\mathrm{a}}$ & $\phi^{\mathrm{b}}$ & ss & $\varepsilon$ \\
\hline \multirow{2}{*}{$\mathbf{2}$} & Toluene & $700,636(\mathrm{sh})^{\mathrm{a}}$ & $716,785(\mathrm{sh})$ & 0.4 & 319 & 206000 \\
& DCM & $694,633(\mathrm{sh})$ & $710,780(\mathrm{sh})$ & 0.34 & 325 & 216000 \\
& DMF & $692,632(\mathrm{sh})$ & $716,780(\mathrm{sh})$ & 0.28 & 375 & 200000 \\
& Acetonitrile & $684,625(\mathrm{sh})$ & $702,770(\mathrm{sh})$ & 0.22 & 484 & 202000 \\
\hline \multirow{3}{*}{$\mathbf{3}$} & Toluene & $864,779(\mathrm{sh})$ & $890,1000(\mathrm{sh})$ & $0.58 \%$ & 338 & 212000 \\
& DCM & $857,772(\mathrm{sh})$ & $886,992(\mathrm{sh})$ & $0.38 \%$ & 331 & 217000 \\
& DMF & $853,772(\mathrm{sh})$ & $896,1001(\mathrm{sh})$ & $0.35 \%$ & 267 & 176000 \\
& Acetonitrile & $843,763(\mathrm{sh})$ & $884,982(\mathrm{sh})$ & $0.37 \%$ & 369 & 186000 \\
\hline \multirow{4}{*}{$\mathbf{4}$} & Toluene & $1002,874(\mathrm{sh})$ & 1071 & $<0.01 \%$ & 643 & 135000 \\
& DCM & $992,868(\mathrm{sh})$ & 1048 & $<0.01 \%$ & 691 & 138000 \\
& DMF & $970,864(\mathrm{sh})$ & 1065 & $<0.01 \%$ & 767 & 92000 \\
& Acetonitrile & $950,852(\mathrm{sh})$ & 1011 & $<0.01 \%$ & 1189 & 95000 \\
\hline
\end{tabular}

${ }^{a}$ The sh means the shoulder peak of the spectrum. ${ }^{b}$ Relative fluorescence quantum yields of $\mathbf{2}$ was calculated using 1,7-diphenyl-3,5- $\operatorname{di}(p$-methoxyphenyl)azadipyrromethene ( $\phi=0.36$ in chloroform) as the reference, 3 and $\mathbf{4}$ were calculated using $\mathrm{ECXb}\left(\phi=0.14\right.$ in $\left.\mathrm{CH}_{2} \mathrm{Cl}_{2}\right)$ as the reference. All of values are corrected for changes in refractive indexes of different solvents. 

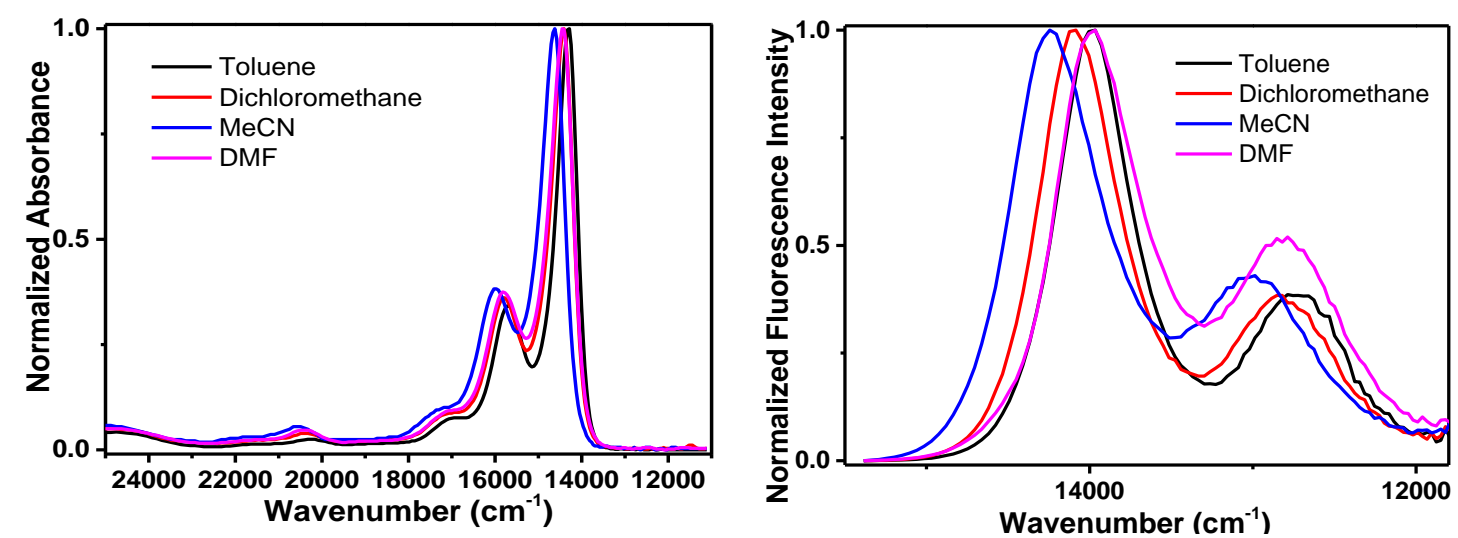

Figure S2. Overlaid normalized absorbance and fluorescence emission spectra of $\mathbf{2}$ in different solvents at room temperature.
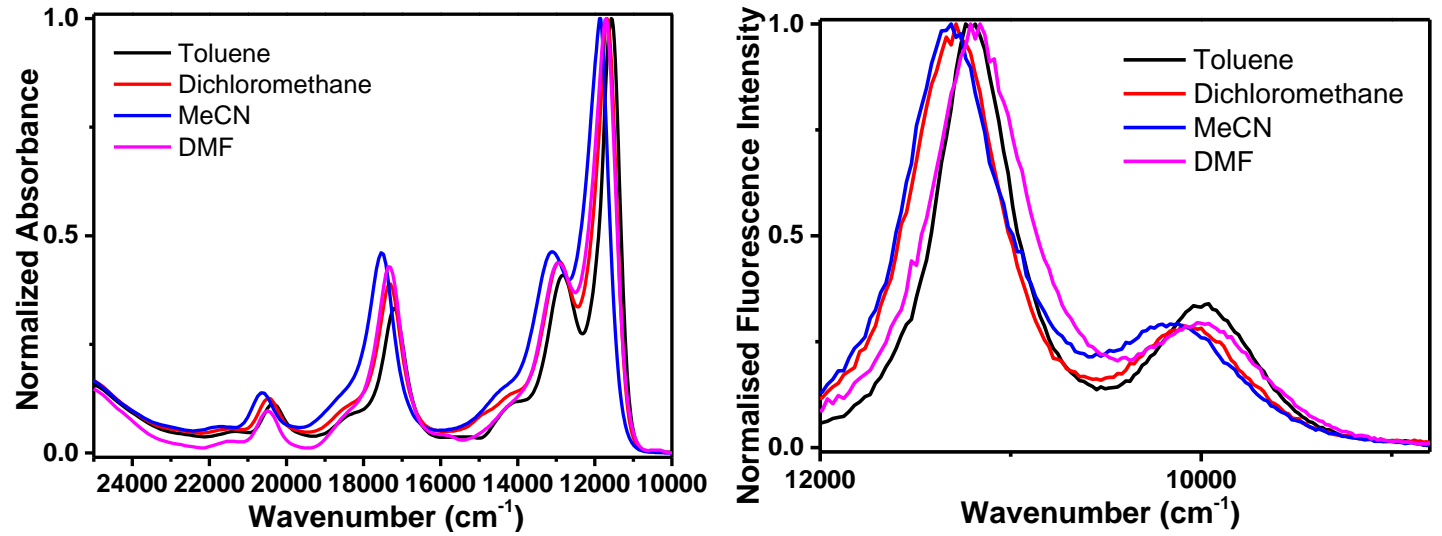

Figure S3. Overlaid normalized absorbance and fluorescence emission spectra of $\mathbf{3}$ in different solvents at room temperature.
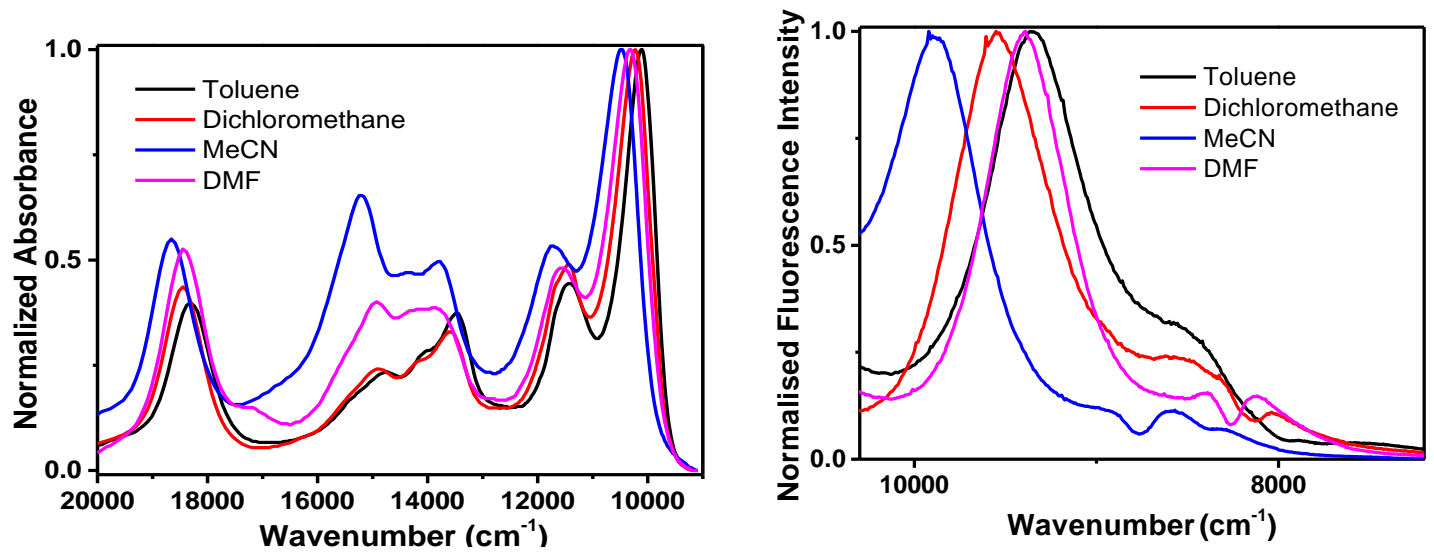

Figure S4. Overlaid normalized absorbance and fluorescence emission spectra of $\mathbf{4}$ in different solvents at room temperature. 


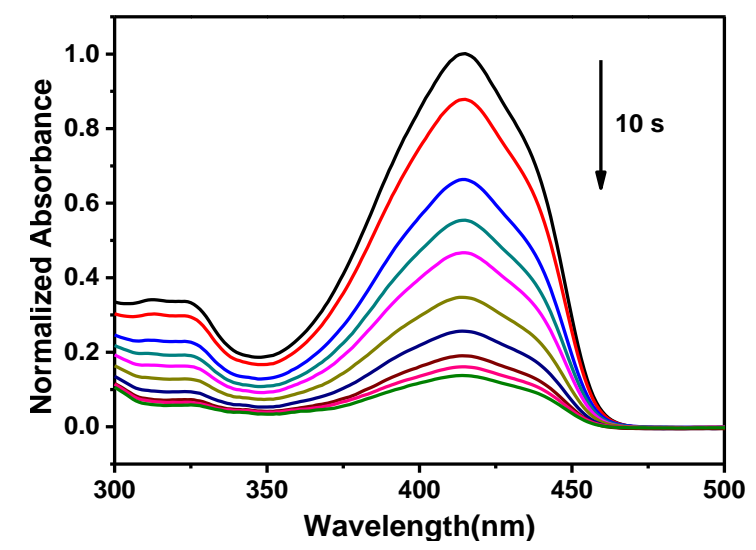

Figure S5. Absorption spectra of DPBF upon irradiation in the presence of 2 in DMF under 660 light exposure at $1 \mathrm{~W} \mathrm{~cm}^{-2}$.

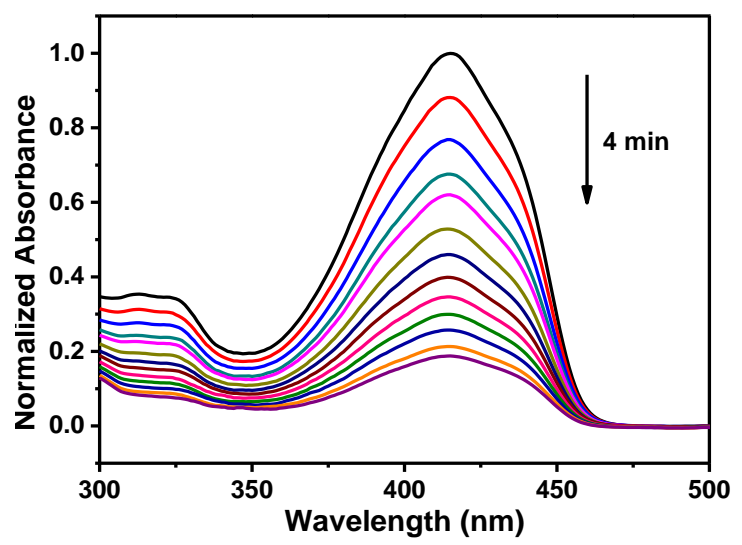

Figure S6. Absorption spectra of DPBF upon irradiation in the presence of 3 in DMF under 808 light exposure at $1 \mathrm{~W} \mathrm{~cm}^{-2}$.

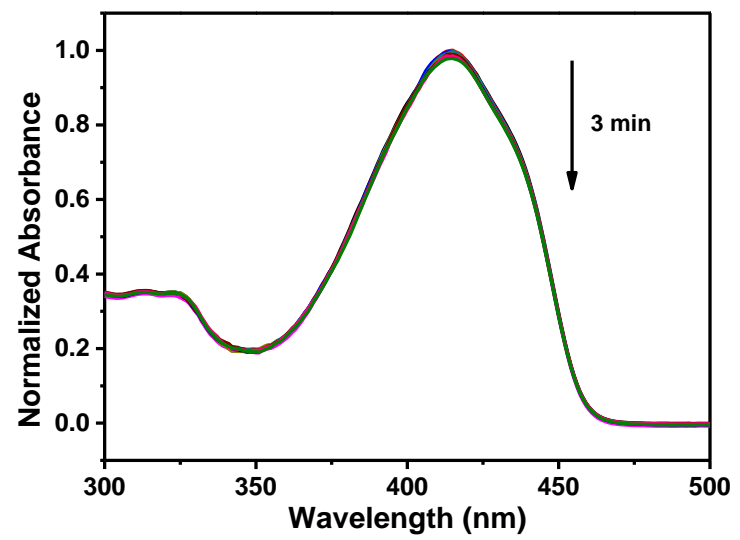

Figure S7. Absorption spectra of DPBF upon irradiation in the presence of 4 in DMF under 980 light exposure at $1 \mathrm{~W} \mathrm{~cm}^{-2}$. 


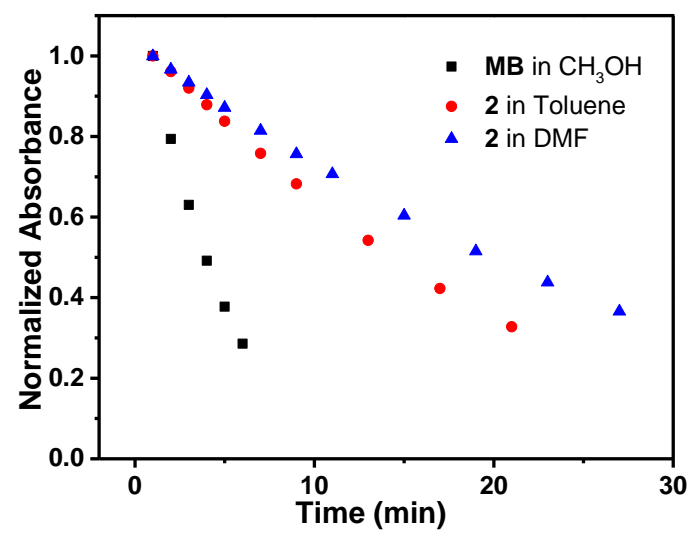

Figure S8. Normalized absorbance of DPBF at $414 \mathrm{~nm}$ of $\mathrm{MB}$ in $\mathrm{CH}_{3} \mathrm{OH}, 2$ in toluene and DMF under 660 light exposure at $1 \mathrm{~mW} \mathrm{~cm}^{-2}$. 


\section{Theoretical Computations}

(a)

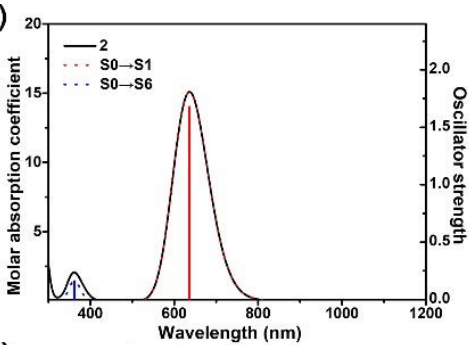

(d)
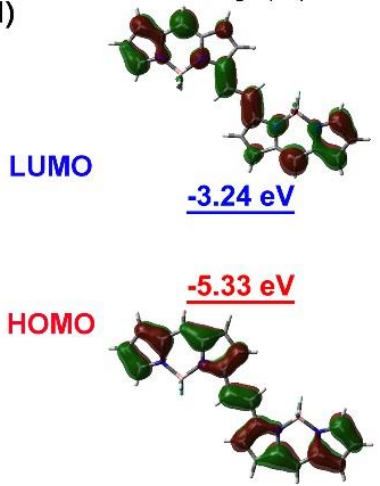

2

$E_{\mathrm{g}} \quad 2.09 \mathrm{eV}$ $\left\langle\mathrm{S}_{1}\left|\hat{\mathrm{H}}_{\mathrm{so}}^{\mathrm{g}}\right| \mathrm{T}_{1}\right\rangle \quad 0.38 \mathrm{~cm}^{-1}$
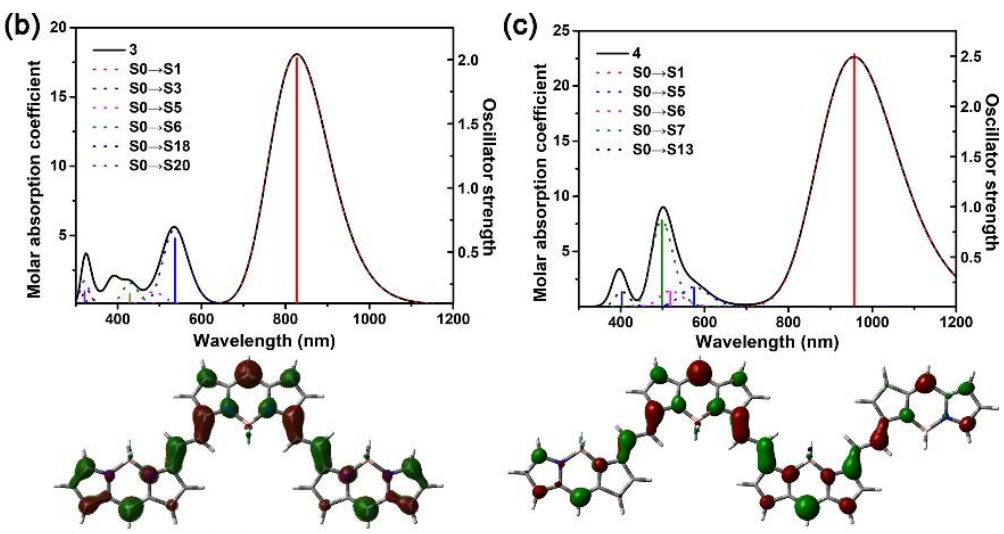

$\underline{-3.42 \mathrm{eV}}$

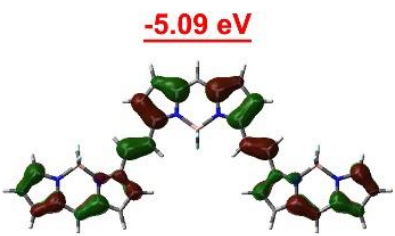

3

$1.67 \mathrm{eV}$

$0.07 \mathrm{~cm}^{-1}$

Reducing $\mathrm{E}_{\mathrm{g}}$ and $\mathrm{SOC}$ values

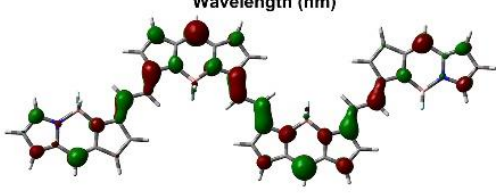

$-3.50 \mathrm{eV}$

$-4.98 \mathrm{eV}$

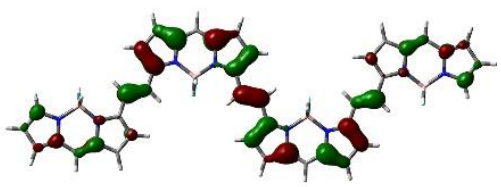

4

$1.48 \mathrm{eV}$

$0.05 \mathrm{~cm}^{-1}$ (e)

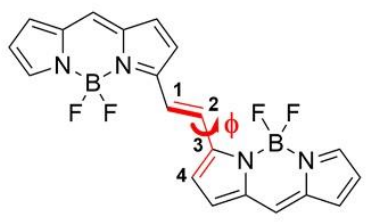

(f)

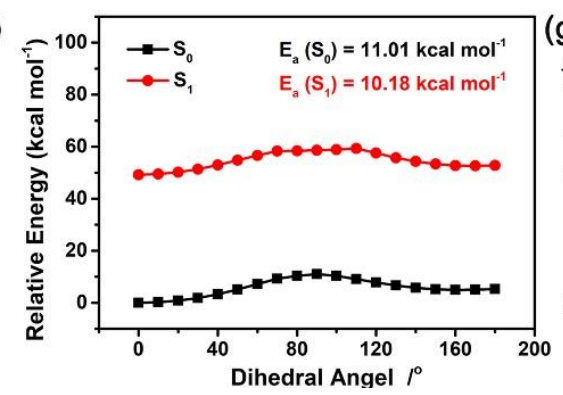

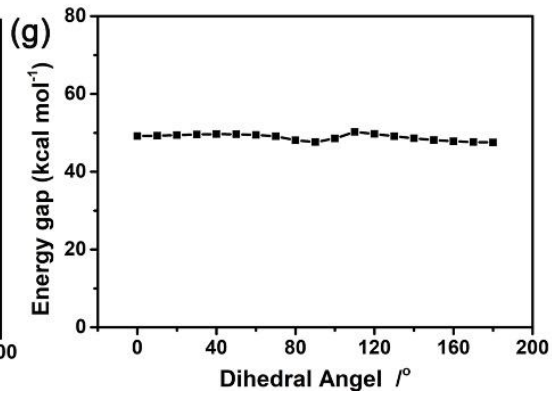

Figure S9. (a-c) Calculated UV-vis absorption and (d) the frontier molecular orbitals (MOs) of the ground-state geometry for $\mathbf{2 , 3}$ and 4 . (e) The dihedral angles $\phi$ for rotation around the $\mathrm{C}-\mathrm{C}$ bond in dimer 2 , (f) energy levels of the $\mathrm{S}_{0}$ (black) and $\mathrm{S}_{1}$ (red) states of the C-C bond in dimer 2 with various dihedral angle, ( $\mathrm{g}$ ) the energy gap between the S0 and S1 states of dimer 2 with dihedral angles $\phi$ around the $\mathrm{C}-\mathrm{C}$ bond. $\mathrm{E}_{\mathrm{a}}$ (energy barrier) stands for the energy barrier between the $S_{0}$ and $S_{1}$ states. The unit for molar absorption coefficient is $10^{4} \mathrm{~L} \mathrm{~mol}^{-1} \mathrm{~cm}^{-1}$. The mesitylene units in the structure were omitted for clarity. 
Table S3. Lowest vertical singlet and triplet electronic transition energies (in eV) and oscillator strengths (in parentheses) of 2-4 at the TD-B3LYP levels, along with vertical singlet-triplet splittings (in $\mathrm{eV}$ ) and SOCs between the involved $\mathrm{T}_{1}$ and $\mathrm{S}_{1}$ states $\left(\mathrm{in} \mathrm{cm}^{-1}\right.$ ).

\begin{tabular}{|c|c|c|c|c|}
\hline oligomers & state/assignment $^{\mathrm{a}}$ & TD-B3LYP & $\Delta \mathrm{E}_{\mathrm{S} 1-\mathrm{T} 1}$ & $\left\langle\mathrm{~S}_{1}\left|\hat{\mathrm{H}}_{\mathrm{SO}}\right| \mathrm{T}_{1}\right\rangle^{\mathrm{b}}$ \\
\hline \multirow{2}{*}{2} & $\mathrm{~S}_{1}(\mathrm{H} \rightarrow \mathrm{L}, \mathrm{c}=0.71 ; \mathrm{H} \leftarrow \mathrm{L}, \mathrm{c}=0.10)$ & $1.95(1.68)$ & - & - \\
\hline & $\mathrm{T}_{1}(\mathrm{H} \rightarrow \mathrm{L}, \mathrm{c}=0.70 ; \mathrm{H} \leftarrow \mathrm{L}, \mathrm{c}=0.14)$ & 0.96 & 0.99 & 0.38 \\
\hline \multirow{2}{*}{3} & $\mathrm{~S}_{1}(\mathrm{H} \rightarrow \mathrm{L}, \mathrm{c}=0.71)$ & $1.5(2.01)$ & - & - \\
\hline & $\mathrm{T}_{1}(\mathrm{H} \rightarrow \mathrm{L}, \mathrm{c}=0.69 ; \mathrm{H} \leftarrow \mathrm{L}, \mathrm{c}=0.15)$ & 0.73 & 0.77 & 0.07 \\
\hline \multirow{2}{*}{4} & $\mathrm{~S}_{1}(\mathrm{H} \rightarrow \mathrm{L}, \mathrm{c}=0.71)$ & $1.30(2.67)$ & - & - \\
\hline & $\mathrm{T}_{1}(\mathrm{H} \rightarrow \mathrm{L}, \mathrm{c}=0.68 ; \mathrm{H} \leftarrow \mathrm{L}, \mathrm{c}=0.16)$ & 0.63 & 0.67 & 0.05 \\
\hline
\end{tabular}

${ }^{a}$ Only the first excited states are considered. ${ }^{b}$ Values are shown as (x component; y component; $\mathrm{z}$ component) and were obtained at the QR-TD-DFT/6-31G* level of theory at the S1 optimized geometry.

Table S4. Calculated SOC values of oligomers 2-4.

\begin{tabular}{c|ccc}
\hline & 2 & 3 & 4 \\
\hline$\left\langle\mathrm{S}_{1}\left|\hat{\mathrm{H}}_{\mathrm{SO}}\right| \mathrm{T}_{1}\right\rangle^{\mathrm{a}}$ & $(0.38 ; 0.00 ; 0.00)$ & $(0.00 ; 0.00 ; 0.07)$ & $(0.01 ; 0.05 ; 0.01)$ \\
\hline$\left\langle\mathrm{S}_{1}\left|\hat{\mathrm{H}}_{\mathrm{SO}}\right| \mathrm{T}_{2}\right\rangle$ & $(0.00 ;-0.20 ;-0.01)$ & $(-0.71 ; 0.00 ; 0.00)$ & $(0.00 ; 0.04 ;-0.03)$ \\
\hline$\left\langle\mathrm{S}_{1}\left|\hat{\mathrm{H}}_{\mathrm{SO}}\right| \mathrm{T}_{3}\right\rangle$ & $(0.00 ; 0.03 ;-0.01)$ & $(0.03 ;-0.01 ;-0.01)$ & $(0.00 ;-0.01 ; 0.00)$ \\
\hline$\left\langle\mathrm{S}_{2}\left|\hat{\mathrm{H}}_{\mathrm{SO}}\right| \mathrm{T}_{1}\right\rangle$ & $(-0.02 ; 0.11 ; 0.00)$ & $(0.23 ; 0.05 ; 0.00)$ & $(0.01 ; 0.09 ;-0.04)$ \\
\hline$\left\langle\mathrm{S}_{2}\left|\hat{\mathrm{H}}_{\mathrm{SO}}\right| \mathrm{T}_{2}\right\rangle$ & $(0.18 ; 0.00 ; 0.00)$ & $(0.00 ; 0.00 ; 0.04)$ & $(0.00 ;-0.09 ; 0.00)$ \\
\hline$\left\langle\mathrm{S}_{2}\left|\hat{\mathrm{H}}_{\mathrm{SO}}\right| \mathrm{T}_{3}\right\rangle$ & $(0.04 ; 0.00 ; 0.00)$ & $(0.00 ; 0.00 ; 0.02)$ & $(0.00 ; 0.01 ; 0.00)$ \\
\hline$\left\langle\mathrm{S}_{3}\left|\hat{\mathrm{H}}_{\mathrm{SO}}\right| \mathrm{T}_{1}\right\rangle$ & $(0.00 ;-0.34 ;-0.01)$ & $(-0.56 ; 0.16 ; 0.00)$ & $(6.55 ;-1.90 ; 0.21)$ \\
\hline$\left\langle\mathrm{S}_{3}\left|\hat{\mathrm{H}}_{\mathrm{SO}}\right| \mathrm{T}_{2}\right\rangle$ & $(-0.18 ; 0.00 ; 0.00)$ & $(0.00 ; 0.00 ; 0.00)$ & $(0.00 ;-0.04 ; 0.02)$ \\
\hline$\left\langle\mathrm{S}_{3}\left|\hat{\mathrm{H}}_{\mathrm{SO}}\right| \mathrm{T}_{3}\right\rangle$ & $(-0.38 ; 0.00 ; 0.00)$ & $(0.00 ; 0.00 ; 0.02)$ & $(0.00 ; 0.05 ; 0.00)$ \\
\hline
\end{tabular}

${ }^{a}$ Values are shown as (x component; y component; $\mathrm{z}$ component) and were obtained at the QR-TD-DFT/6-31G* level of theory at the $\mathrm{S}_{1}$ optimized geometry. 
Table S5. Selected electronic excitation energies (eV) and oscillator strengths (f), configurations of the low-lying singlet excited states of oligomers 2-4 calculated by TDDFT//B3LYP/6-31+G(d, p), based on the optimized ground state geometries.

\begin{tabular}{|c|c|c|c|c|c|}
\hline \multirow{2}{*}{ oligmers } & \multirow{2}{*}{$\begin{array}{l}\text { Electronic } \\
\text { transition }\end{array}$} & \multicolumn{4}{|c|}{ TD//B3LYP/6-31+G(d, p) } \\
\hline & & Energy/ e V ${ }^{\text {[a] }}$ & $f^{[\mathrm{b}]}$ & Composition $^{[c]}$ & $\mathrm{CI}^{[\mathrm{d}]}$ \\
\hline \multirow[t]{6}{*}{2} & $\mathrm{~S} 0 \rightarrow \mathrm{S} 1$ & $1.9491 \mathrm{eV} \quad 636.11 \mathrm{~nm}$ & 1.6792 & $\mathrm{HOMO} \rightarrow$ LUMO & 0.7110 \\
\hline & & & & $\mathrm{HOMO} \leftarrow$ LUMO & 0.1021 \\
\hline & $\mathrm{S} 0 \rightarrow \mathrm{S} 2$ & $2.4773 \mathrm{eV} 500.48 \mathrm{~nm}$ & 0.0000 & HOMO - $1 \rightarrow$ LUMO & 0.4994 \\
\hline & & & & $\mathrm{HOMO} \rightarrow \mathrm{LUMO}+1$ & 0.4976 \\
\hline & $\mathrm{S} 0 \rightarrow \mathrm{S} 3$ & $2.9117 \mathrm{eV} \quad 425.81 \mathrm{~nm}$ & 0.0000 & HOMO - $1 \rightarrow$ LUMO & 0.4726 \\
\hline & & & & $\mathrm{HOMO} \rightarrow \mathrm{LUMO}+1$ & 0.4712 \\
\hline \multirow[t]{5}{*}{3} & $\mathrm{~S} 0 \rightarrow \mathrm{S} 1$ & $1.4999 \mathrm{eV} 826.62 \mathrm{~nm}$ & 2.0117 & $\mathrm{HOMO} \rightarrow$ LUMO & 0.7100 \\
\hline & $\mathrm{S} 0 \rightarrow \mathrm{S} 2$ & $1.9302 \mathrm{eV} 642.35 \mathrm{~nm}$ & 0.0007 & HOMO - $1 \rightarrow$ LUMO & 0.4820 \\
\hline & & & & $\mathrm{HOMO} \rightarrow \mathrm{LUMO}+1$ & 0.5122 \\
\hline & $\mathrm{S} 0 \rightarrow \mathrm{S} 3$ & $2.3130 \mathrm{eV} 536.04 \mathrm{~nm}$ & 0.6063 & HOMO $-1 \rightarrow$ LUMO & 0.5159 \\
\hline & & & & $\mathrm{HOMO} \rightarrow \mathrm{LUMO}+1$ & 0.4881 \\
\hline \multirow[t]{5}{*}{4} & $\mathrm{~S} 0 \rightarrow \mathrm{S} 1$ & $1.2953 \mathrm{eV} 956.18 \mathrm{~nm}$ & 2.6696 & HOMO $\rightarrow$ LUMO & 0.7080 \\
\hline & $\mathrm{S} 0 \rightarrow \mathrm{S} 2$ & $1.6396 \mathrm{eV} 756.17 \mathrm{~nm}$ & 0.0000 & HOMO - $1 \rightarrow$ LUMO & 0.4840 \\
\hline & & & & $\mathrm{HOMO} \rightarrow \mathrm{LUMO}+1$ & 0.5082 \\
\hline & $\mathrm{S} 0 \rightarrow \mathrm{S} 3$ & $1.9486 \mathrm{eV} 636.26 \mathrm{~nm}$ & 0.0087 & HOMO - $1 \rightarrow$ LUMO & 0.5167 \\
\hline & & & & $\mathrm{HOMO} \rightarrow \mathrm{LUMO}+1$ & 0.4936 \\
\hline
\end{tabular}

[a] Only the selected low-lying excited states are presented. [b] Oscillator strength. [c] Only the main configurations are presented. [d] The CI coefficients are in absolute values. 
Table S6. Selected electronic excitation energies (eV) and oscillator strengths (f), configurations of the low-lying triplet excited states of oligomers 2-4 calculated by TDDFT//B3LYP/6-31+G(d, p), based on the optimized ground state geometries.

\begin{tabular}{|c|c|c|c|c|c|}
\hline \multirow{2}{*}{ oligmers } & \multirow{2}{*}{$\begin{array}{l}\text { Electronic } \\
\text { transition }\end{array}$} & \multicolumn{4}{|c|}{ TD//B3LYP/6-31+G(d, p) } \\
\hline & & Energy/ eV ${ }^{\text {[a] }}$ & $f^{[\mathbf{b}]}$ & Composition $^{[\mathrm{c}]}$ & $\mathrm{CI}^{[\mathrm{d}]}$ \\
\hline \multirow[t]{6}{*}{2} & $\mathrm{~S} 0 \rightarrow \mathrm{T} 1$ & $0.9622 \mathrm{eV} 1288.60 \mathrm{~nm}$ & 0.0000 & $\mathrm{HOMO} \rightarrow \mathrm{LUMO}$ & 0.6993 \\
\hline & & & & $\mathrm{HOMO} \leftarrow$ LUMO & 0.1424 \\
\hline & $\mathrm{S} 0 \rightarrow \mathrm{T} 2$ & $1.6037 \mathrm{eV} 773.09 \mathrm{~nm}$ & 0.0000 & HOMO $-1 \rightarrow$ LUMO & 0.4742 \\
\hline & & & & $\mathrm{HOMO} \rightarrow \mathrm{LUMO}+1$ & 0.5225 \\
\hline & $\mathrm{S} 0 \rightarrow \mathrm{T} 3$ & $2.2688 \mathrm{eV} 546.47 \mathrm{~nm}$ & 0.0000 & HOMO - $1 \rightarrow$ LUMO & 0.5117 \\
\hline & & & & $\mathrm{HOMO} \rightarrow \mathrm{LUMO}+1$ & 0.4601 \\
\hline \multirow[t]{6}{*}{3} & $\mathrm{~S} 0 \rightarrow \mathrm{T} 1$ & $0.7306 \mathrm{eV} 1697.11 \mathrm{~nm}$ & 0.0000 & $\mathrm{HOMO} \rightarrow$ LUMO & 0.6944 \\
\hline & & & & $\mathrm{HOMO} \leftarrow$ LUMO & 0.1537 \\
\hline & $\mathrm{S} 0 \rightarrow \mathrm{T} 2$ & $1.2126 \mathrm{eV} 1022.45 \mathrm{~nm}$ & 0.0007 & HOMO -1 $\rightarrow$ LUMO & 0.4786 \\
\hline & & & & $\mathrm{HOMO} \rightarrow \mathrm{LUMO}+1$ & 0.4856 \\
\hline & $\mathrm{S} 0 \rightarrow \mathrm{T} 3$ & $1.6067 \mathrm{eV} 771.69 \mathrm{~nm}$ & 0.0000 & HOMO $-1 \rightarrow$ LUMO +1 & 0.3801 \\
\hline & & & & $\mathrm{HOMO} \rightarrow \mathrm{LUMO}+2$ & 0.4479 \\
\hline \multirow[t]{7}{*}{4} & $\mathrm{~S} 0 \rightarrow \mathrm{T} 1$ & $0.6257 \mathrm{eV} 1981.56 \mathrm{~nm}$ & 0.0000 & $\mathrm{HOMO} \rightarrow$ LUMO & 0.6839 \\
\hline & & & & $\mathrm{HOMO} \leftarrow$ LUMO & 0.1563 \\
\hline & $\mathrm{S} 0 \rightarrow \mathrm{T} 2$ & $0.9700 \mathrm{eV} 1278.22 \mathrm{~nm}$ & 0.0000 & HOMO -1 $\rightarrow$ LUMO & 0.4816 \\
\hline & & & & $\mathrm{HOMO} \rightarrow \mathrm{LUMO}+1$ & 0.4805 \\
\hline & $\mathrm{S} 0 \rightarrow \mathrm{T} 3$ & $1.3381 \mathrm{eV} 926.60 \mathrm{~nm}$ & 0.0000 & HOMO $-2 \rightarrow$ LUMO & 0.3821 \\
\hline & & & & $\mathrm{HOMO} \rightarrow \mathrm{LUMO}+2$ & 0.3934 \\
\hline & & & & HOMO $-1 \rightarrow$ LUMO +1 & 0.3804 \\
\hline
\end{tabular}

[a] Only the selected low-lying excited states are presented. [b] Oscillator strength. [c] Only the main configurations are presented. [d] The CI coefficients are in absolute values. 


\section{Characterization and Properties of Nanoparticles}

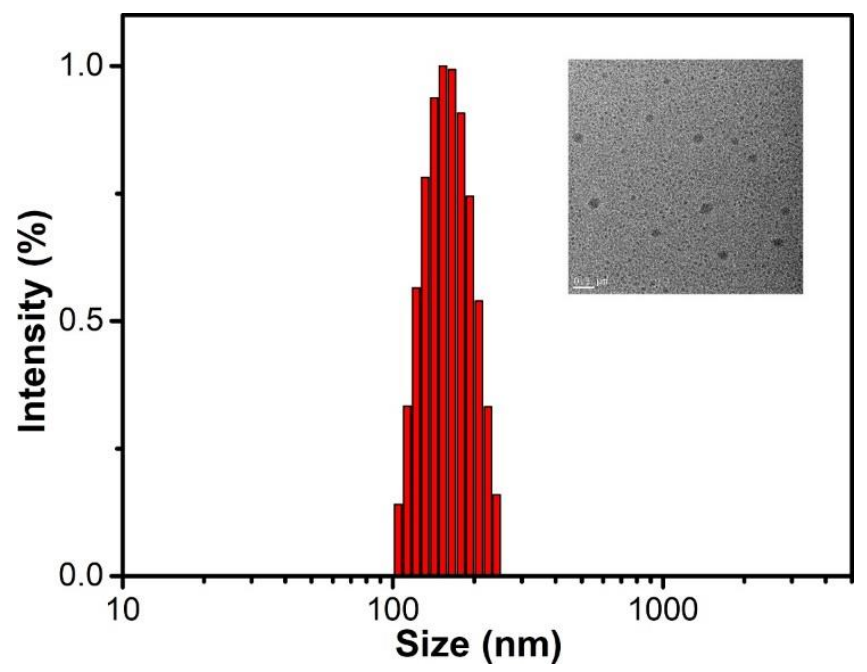

Figure S10. Size distribution of 2-NPs. The inset shows the TEM image of 2-NPs, the scale bar is $0.5 \mu \mathrm{m}$.

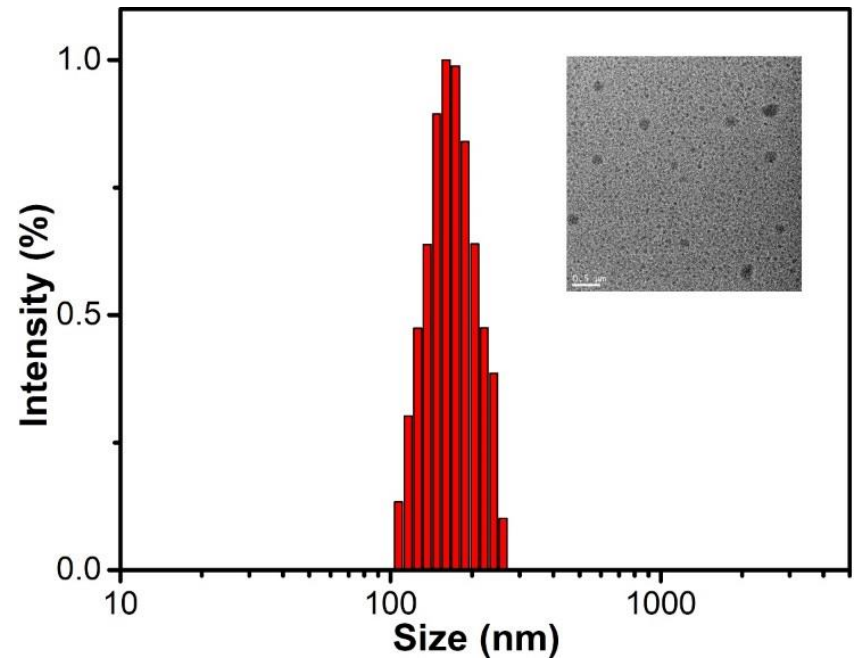

Figure S11. Size distribution of 4-NPs. The inset shows the TEM image of 4-NPs, the scale bar is $0.5 \mu \mathrm{m}$. 


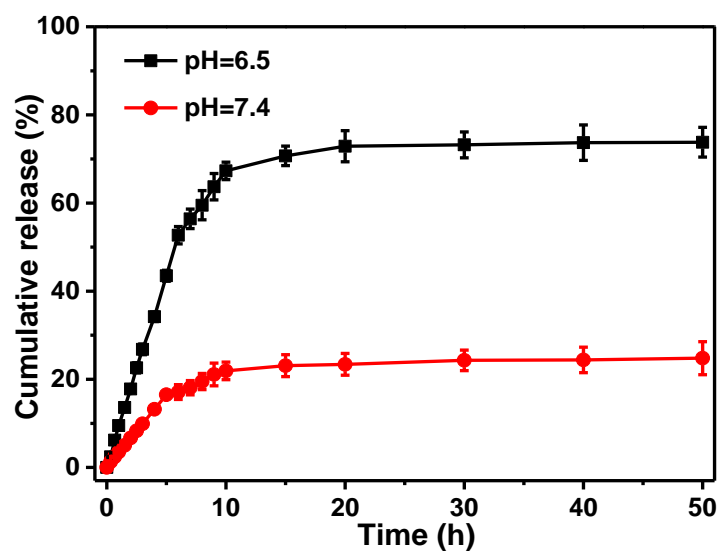

Figure S12. In vitro drug release profile of 2-NPs at $\mathrm{pH} 7.4$ or 6.5. The results are shown as the mean $\pm \operatorname{SD}(n=3)$.

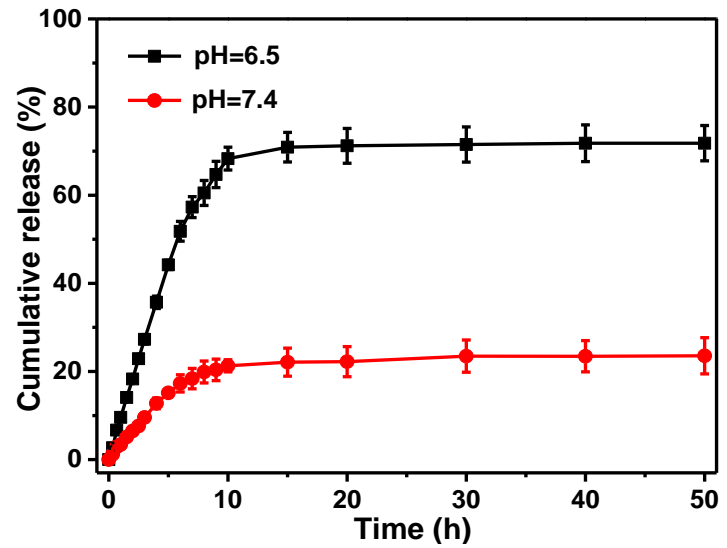

Figure S13. In vitro drug release profile of 3-NPs at $\mathrm{pH} 7.4$ or 6.5. The results are shown as the mean $\pm \operatorname{SD}(n=3)$.

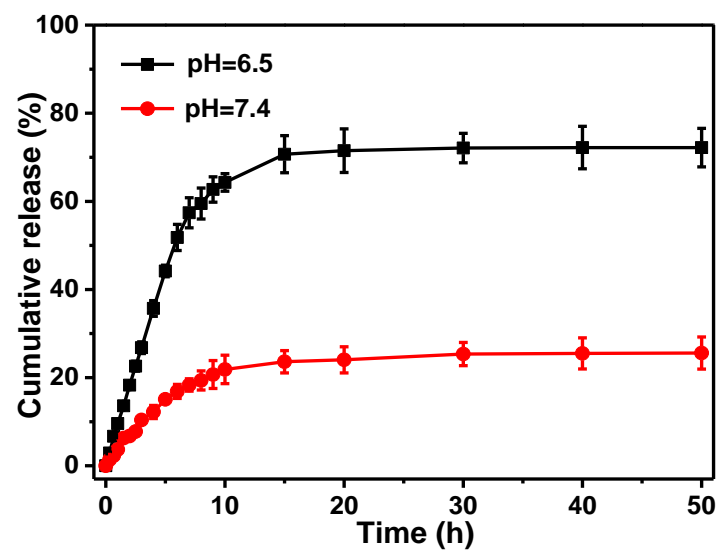

Figure S14. In vitro drug release profile of 4-NPs at $\mathrm{pH} 7.4$ or 6.5. The results are shown as the mean $\pm \operatorname{SD}(n=3)$. 

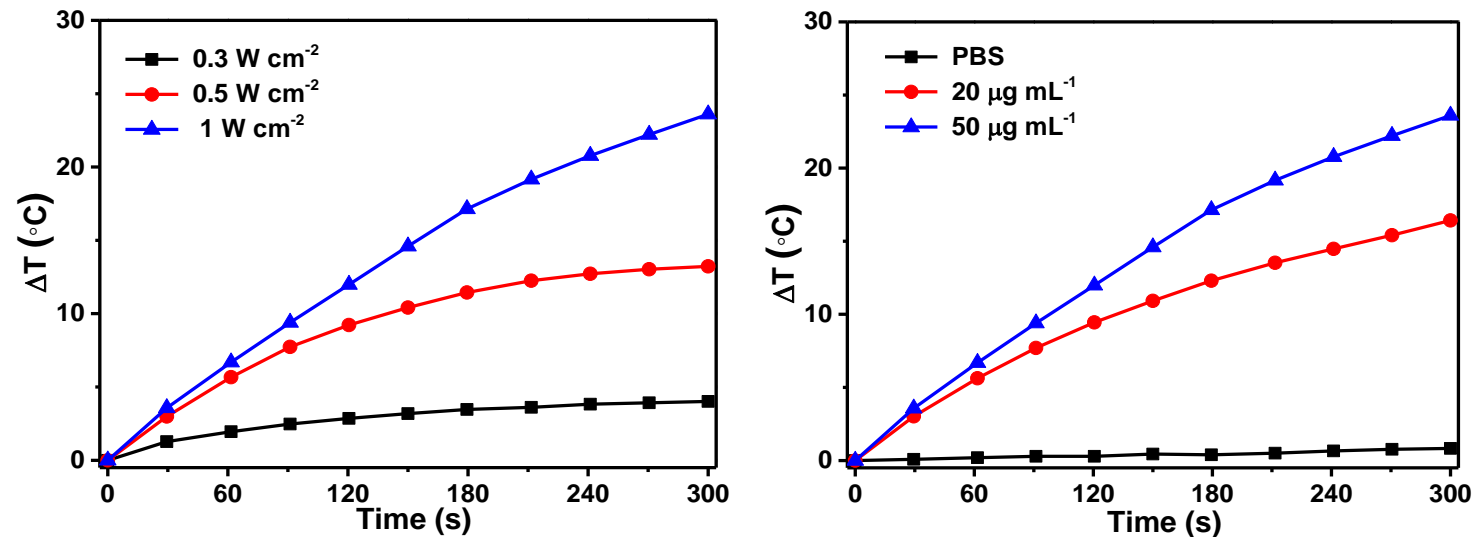

Figure S15. Temperature changes for 2-NPs $\left(50 \mu \mathrm{g} \mathrm{mL}^{-1}\right)$ of different laser powers after $660 \mathrm{~nm}$ laser irradiation and temperature change for 2-NPs of different concentrations after $660 \mathrm{~nm}$ laser irradiation $\left(1 \mathrm{~W} \mathrm{~cm}^{-2}\right)$.
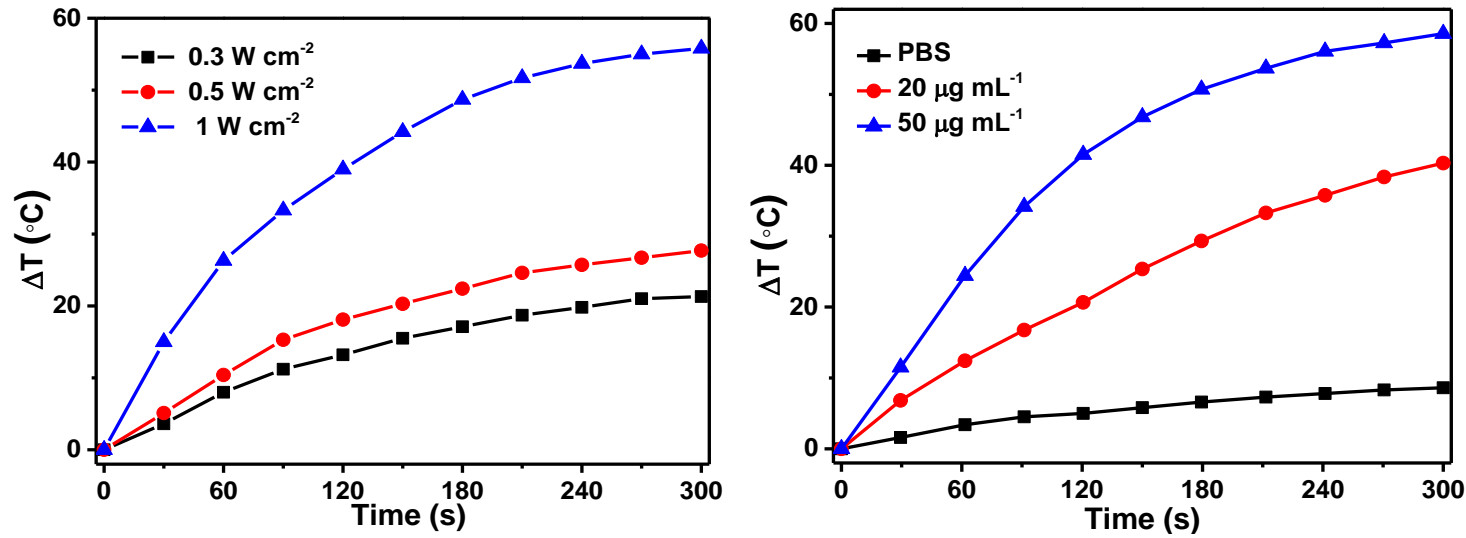

Figure S16. Temperature change for 4-NPs $\left(50 \mu \mathrm{g} \mathrm{mL} L^{-1}\right)$ of different laser powers after $980 \mathrm{~nm}$ laser irradiation. Temperature change for 4-NPs of different concentrations after $980 \mathrm{~nm}$ laser irradiation $\left(1 \mathrm{~W} \mathrm{~cm}^{-2}\right)$. 

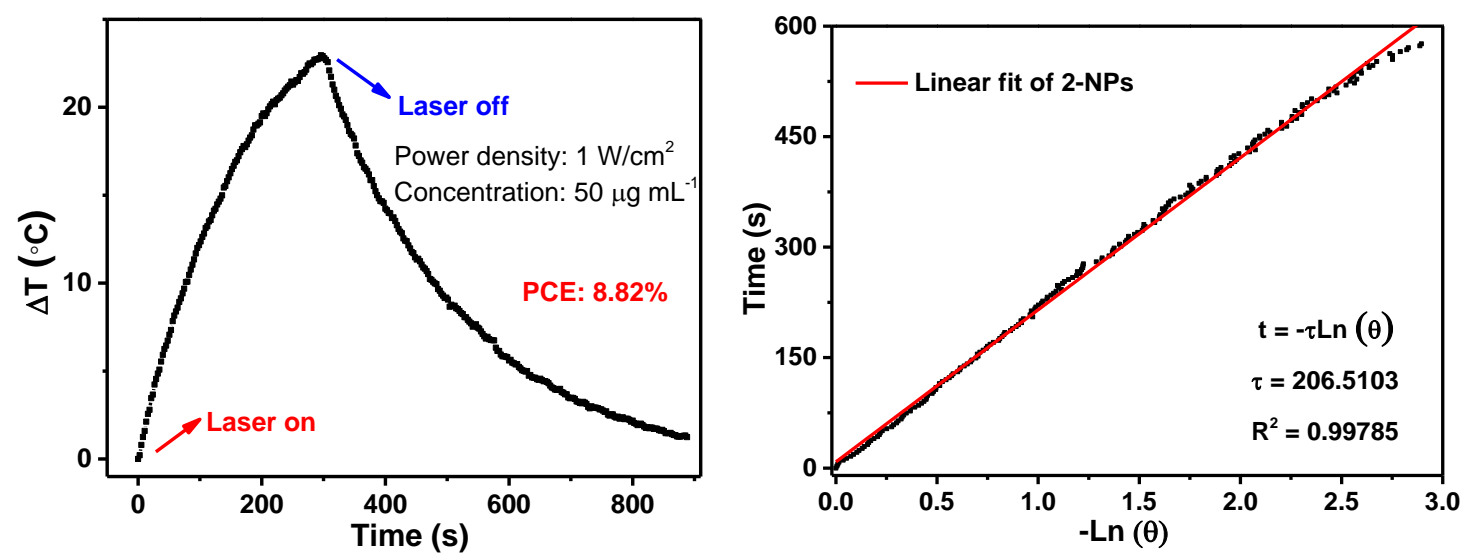

Figure S17. Photothermal effect of 2-NPs upon laser irradiation $\left(1 \mathrm{~W} \mathrm{~cm}^{-2}\right)$ which was turned off after irradiation for 10 minutes and plot of cooling time vs. negative natural logarithm of the temperature change obtained from the cooling stage.
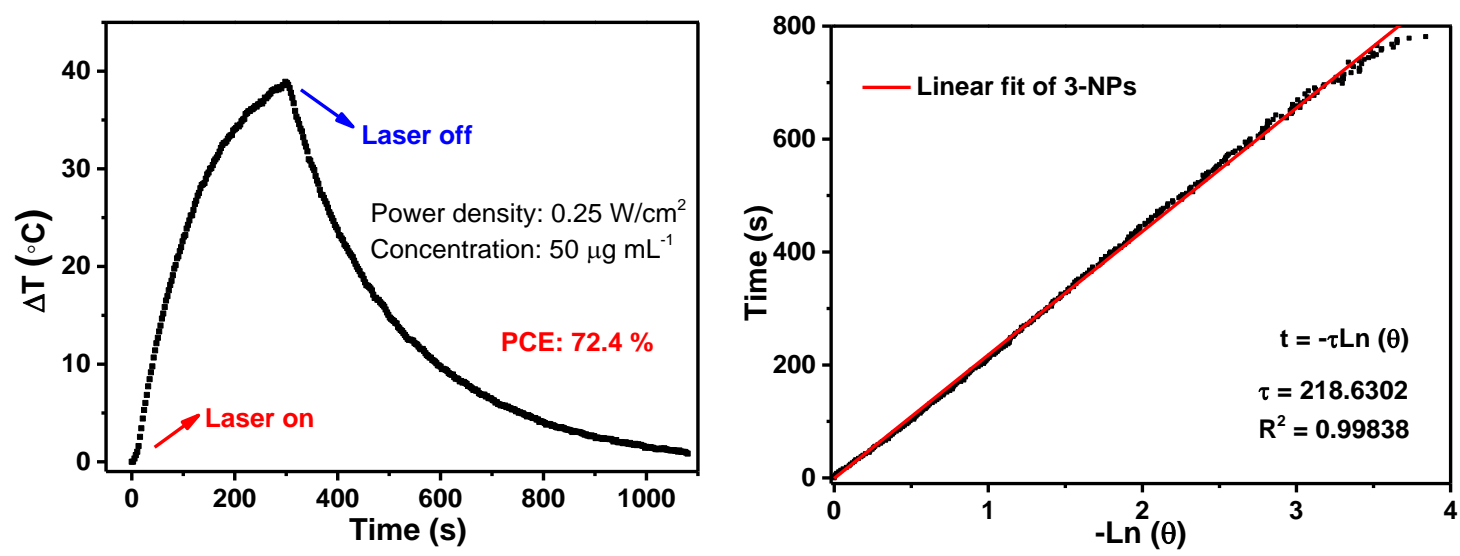

Figure S18. Photothermal effect of 3-NPs upon laser irradiation $\left(0.25 \mathrm{~W} \mathrm{~cm}^{-2}\right)$ which was turned off after irradiation for 13 minutes and plot of cooling time vs. negative natural logarithm of the temperature change obtained from the cooling stage.
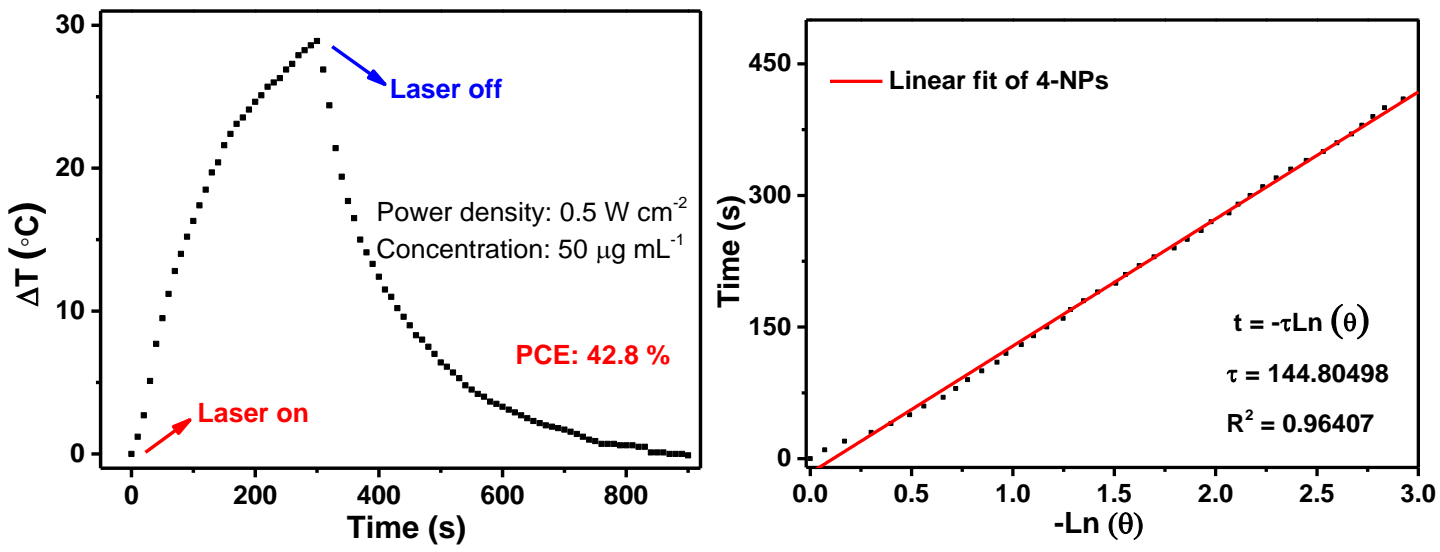
Figure S19. Photothermal effect of 4-NPs upon laser irradiation $\left(0.5 \mathrm{~W} \mathrm{~cm}^{-2}\right)$ which was turned off after irradiation for 9 minutes and plot of cooling time vs. negative natural logarithm of the temperature change obtained from the cooling stage.

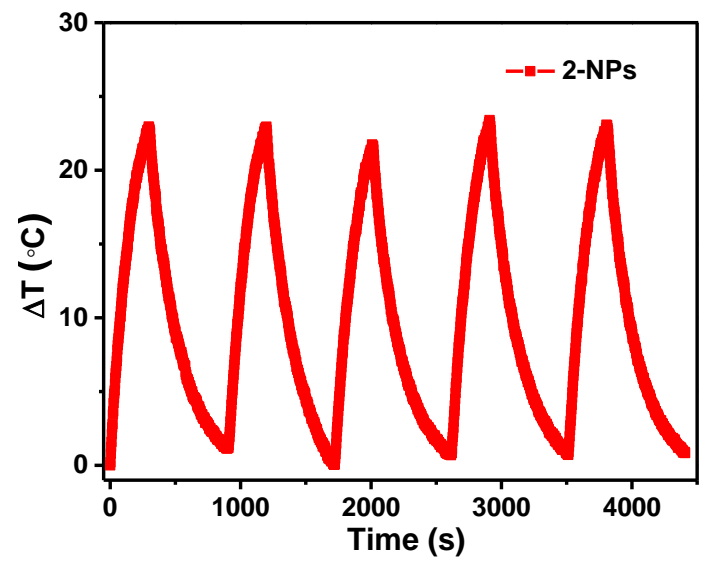

Figure S20. Temperature evolutions of the 2-NPs under laser irradiation $\left(1 \mathrm{~W} \mathrm{~cm}^{-2}\right)$ for 5 laser on/off cycles.

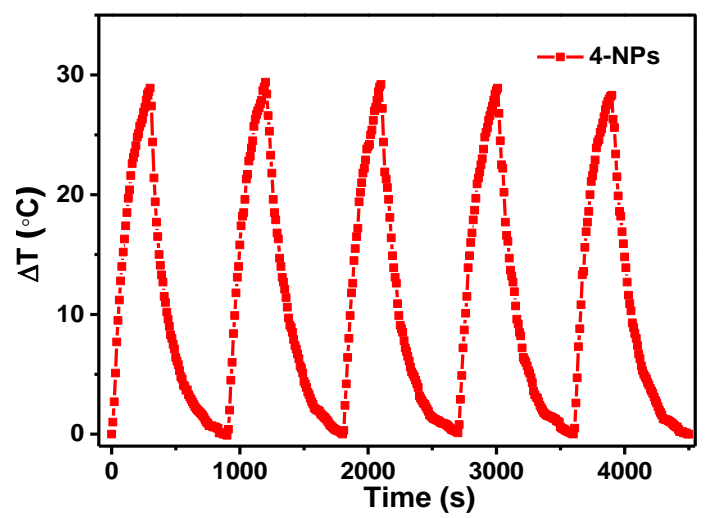

Figure S21. Temperature evolutions of the 4-NPs under laser irradiation $\left(0.5 \mathrm{~W} \mathrm{~cm}^{-2}\right)$ for 5 laser on/off cycles. 


\section{Targeted Multifunctional Imaging Properties of Nanoparticles}

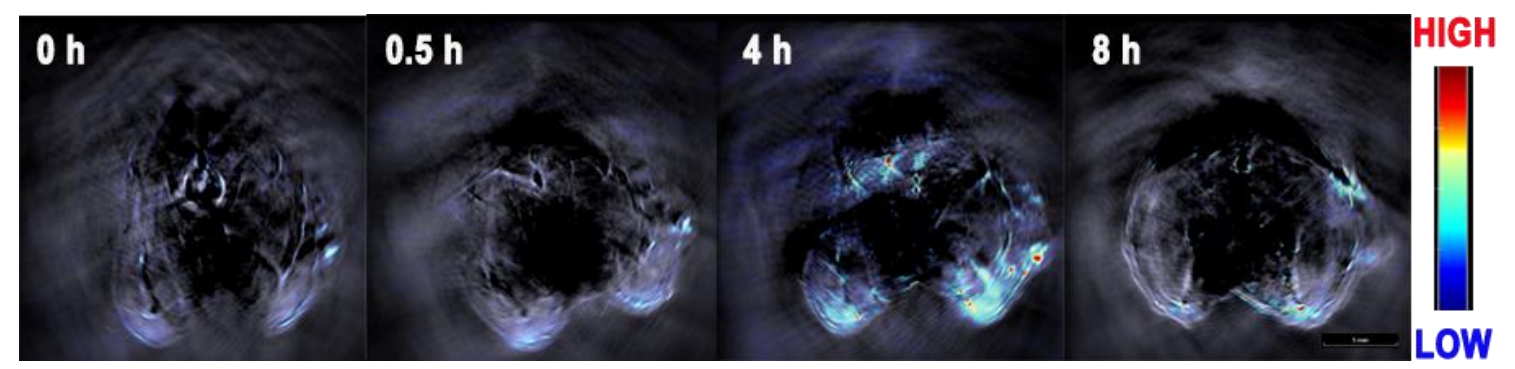

Figure S22. Time-dependent in vivo PA imaging of $4 \mathrm{~T} 1$ tumor excited by a $750 \mathrm{~nm}$ pulsed laser after the intravenous injection of 2-NPs $\left(0.5 \mathrm{mg} \mathrm{kg}^{-1}\right.$ of body weight). The scale bar represents $5 \mathrm{~mm}$.

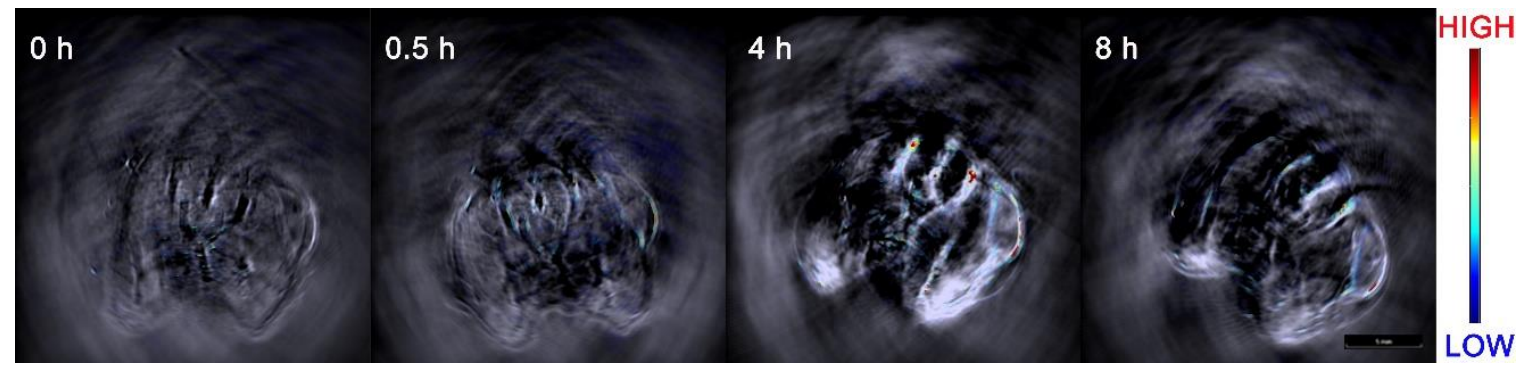

Figure S23. Time-dependent in vivo PA imaging of $4 \mathrm{~T} 1$ tumor excited by a $808 \mathrm{~nm}$ pulsed laser after the intravenous injection of 3-NPs $\left(0.5 \mathrm{mg} \mathrm{kg}^{-1}\right.$ of body weight). The scale bar represents $5 \mathrm{~mm}$.

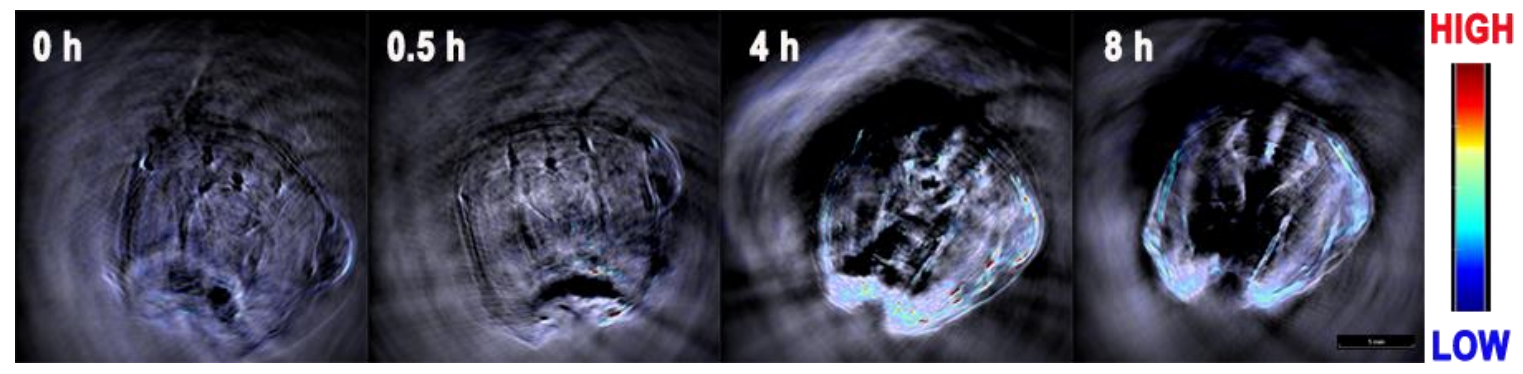

Figure S24. Time-dependent in vivo PA imaging of $4 \mathrm{~T} 1$ tumor excited by a $950 \mathrm{~nm}$ pulsed laser after the intravenous injection of 4-NPs $\left(0.5 \mathrm{mg} \mathrm{kg}^{-1}\right.$ of body weight). The scale bar represents $5 \mathrm{~mm}$. 


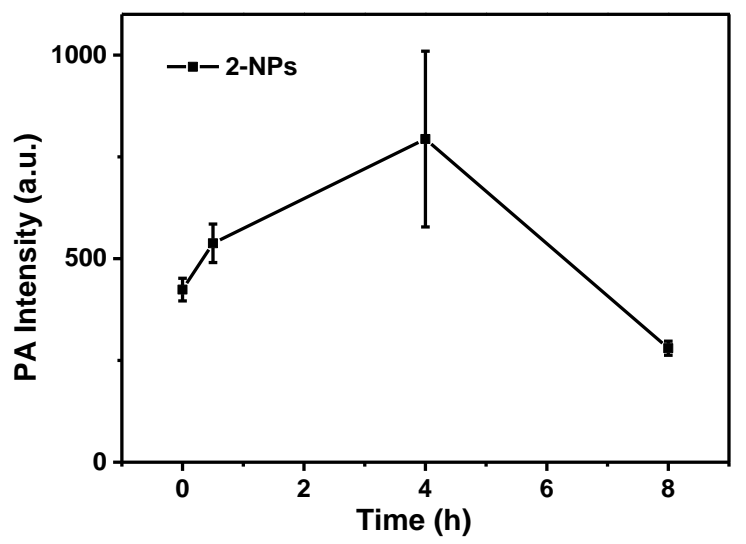

Figure S25. Time-dependent in vivo PA intensities of $4 \mathrm{~T} 1$ tumor excited by a $750 \mathrm{~nm}$ pulsed laser after the intravenous injection of 2-NPs $\left(0.5 \mathrm{mg} \mathrm{kg}^{-1}\right.$ of body weight $)$.

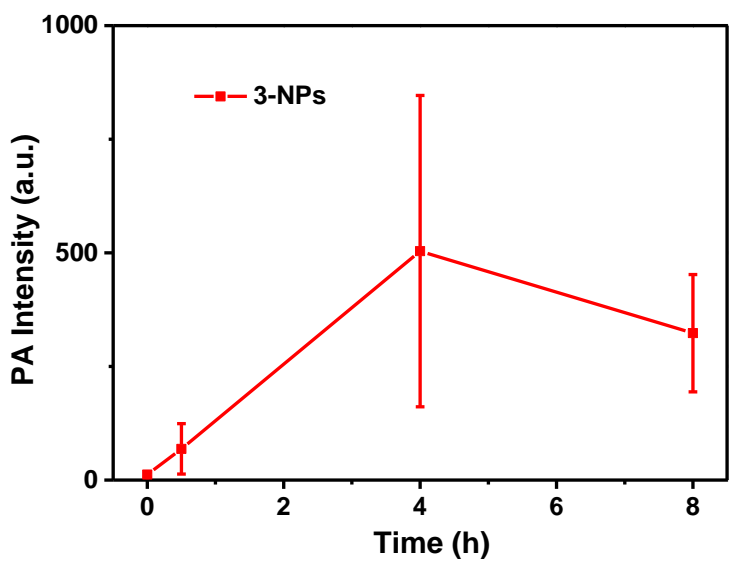

Figure S26. Time-dependent in vivo PA intensities of 4T1 tumor excited by a $808 \mathrm{~nm}$ pulsed laser after the intravenous injection of 3-NPs $\left(0.5 \mathrm{mg} \mathrm{kg}^{-1}\right.$ of body weight).

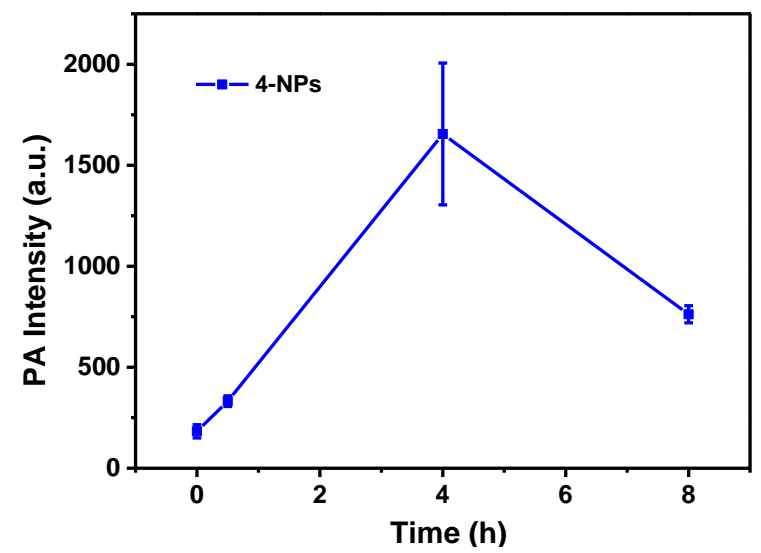

Figure S27. Time-dependent in vivo PA intensities of $4 \mathrm{~T} 1$ tumor excited by a $950 \mathrm{~nm}$ pulsed laser after the intravenous injection of 4-NPs $\left(0.5 \mathrm{mg} \mathrm{kg}^{-1}\right.$ of body weight). 


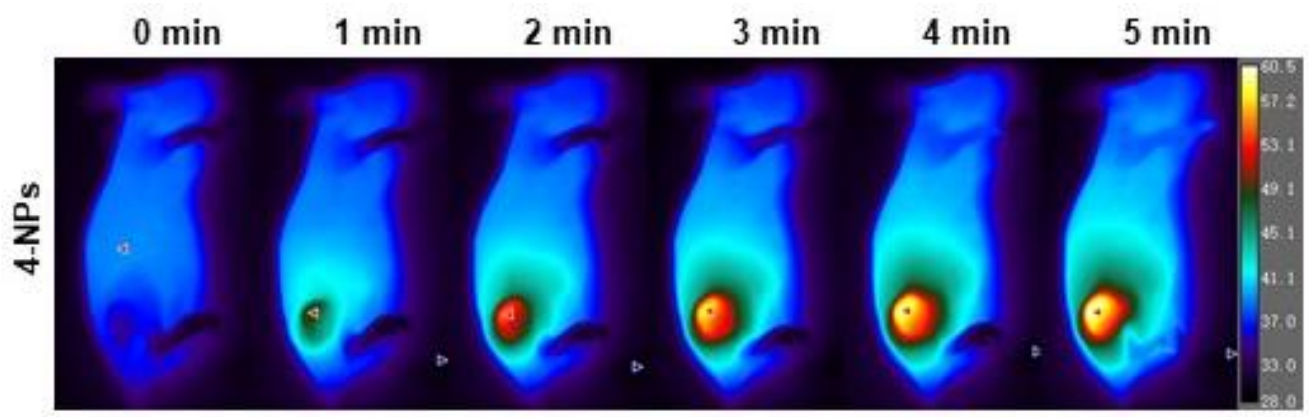

Figure 28. Infrared thermal images of the mice intratumorly injected with $125 \mu \mathrm{L}$ 4-NPs $\left(50 \mu \mathrm{g} \mathrm{mL}^{-1}\right)$ under $980 \mathrm{~nm}$ light exposure at $1 \mathrm{~W} \mathrm{~cm}^{-2}$ for 5 min captured at different time intervals. 


\section{In Vivo Phototherapy of Nanoparticles}

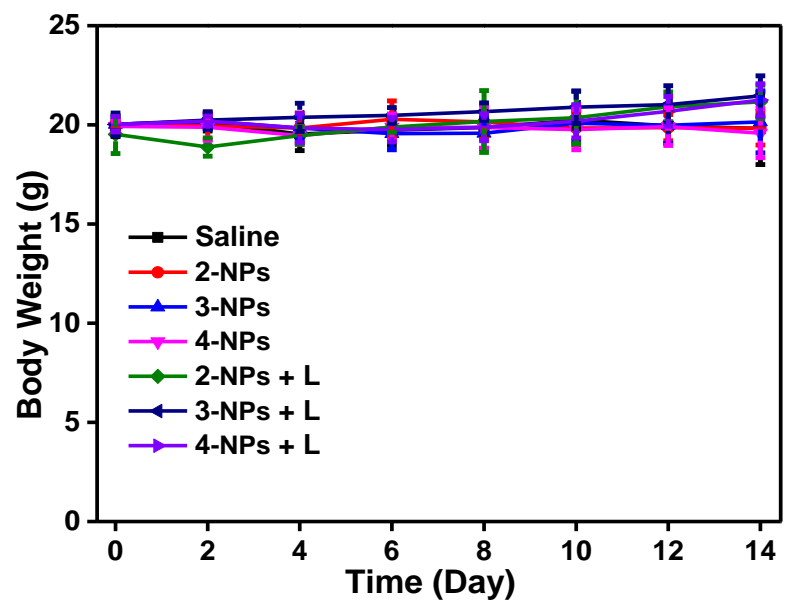

Figure S29. Phototherapy in vivo. Body weight changes of mice during therapy.

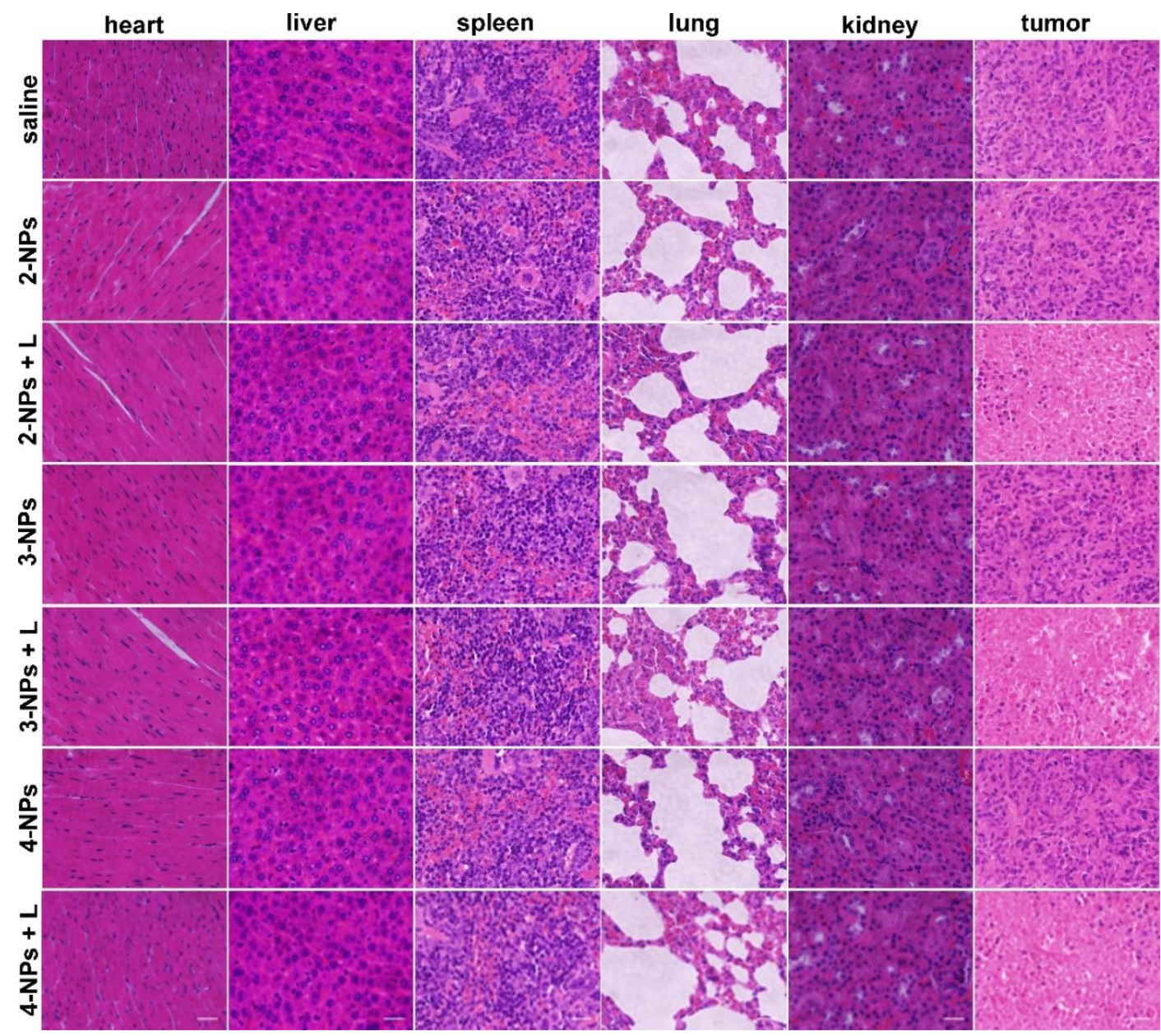

Figure S30. H\&E staining on the tumor sections and major organs of the mice after therapy. Scale bar: $50 \mu \mathrm{m}$. 


\section{8. ${ }^{1} \mathrm{H}$ NMR, ${ }^{13} \mathrm{C}$ NMR and HRMS for all new compounds}

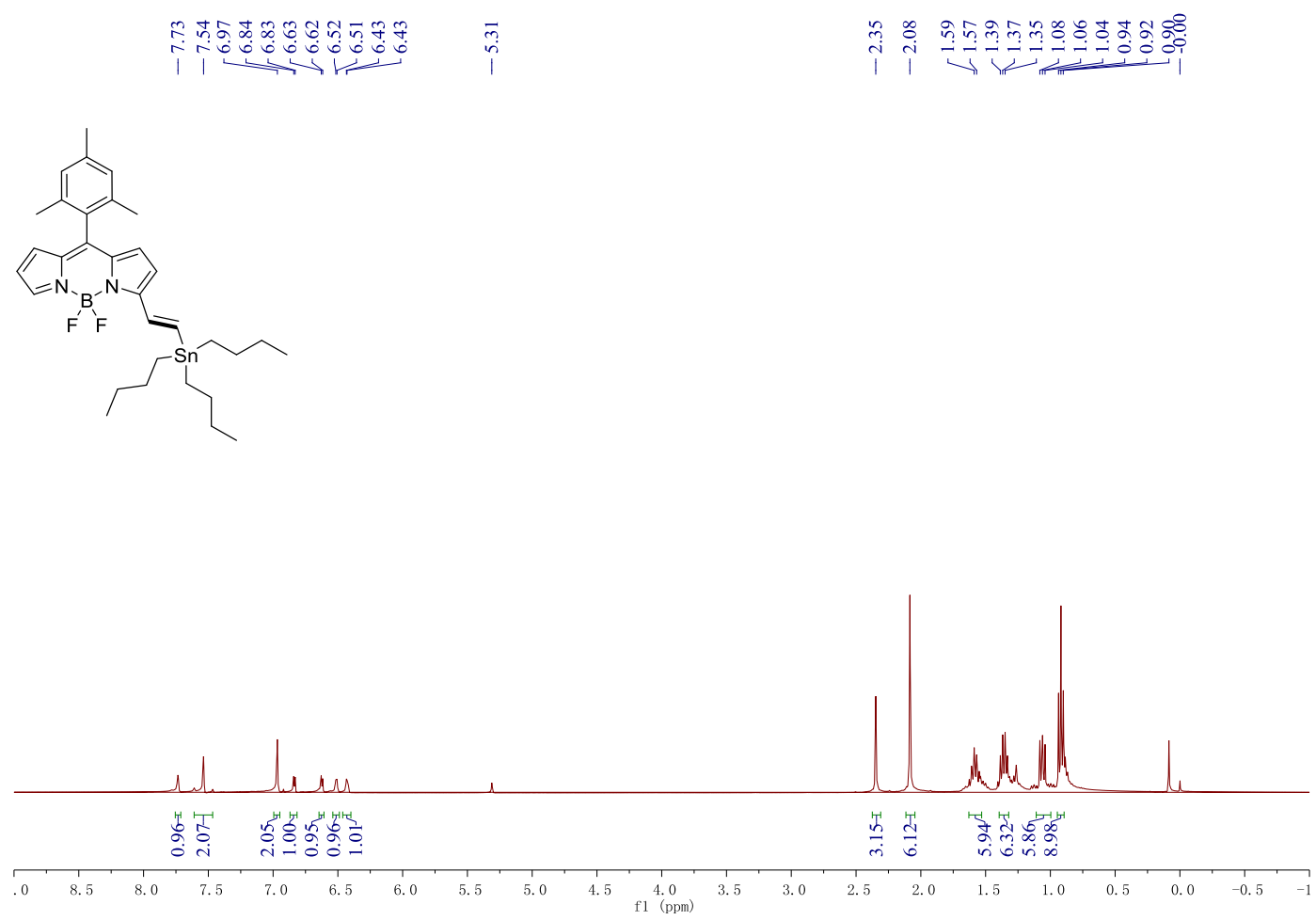

Figure S31. ${ }^{1} \mathrm{H}$ NMR (400 MHz) spectrum of $\mathbf{1 S n}$ in $\mathrm{CD}_{2} \mathrm{Cl}_{2}$.
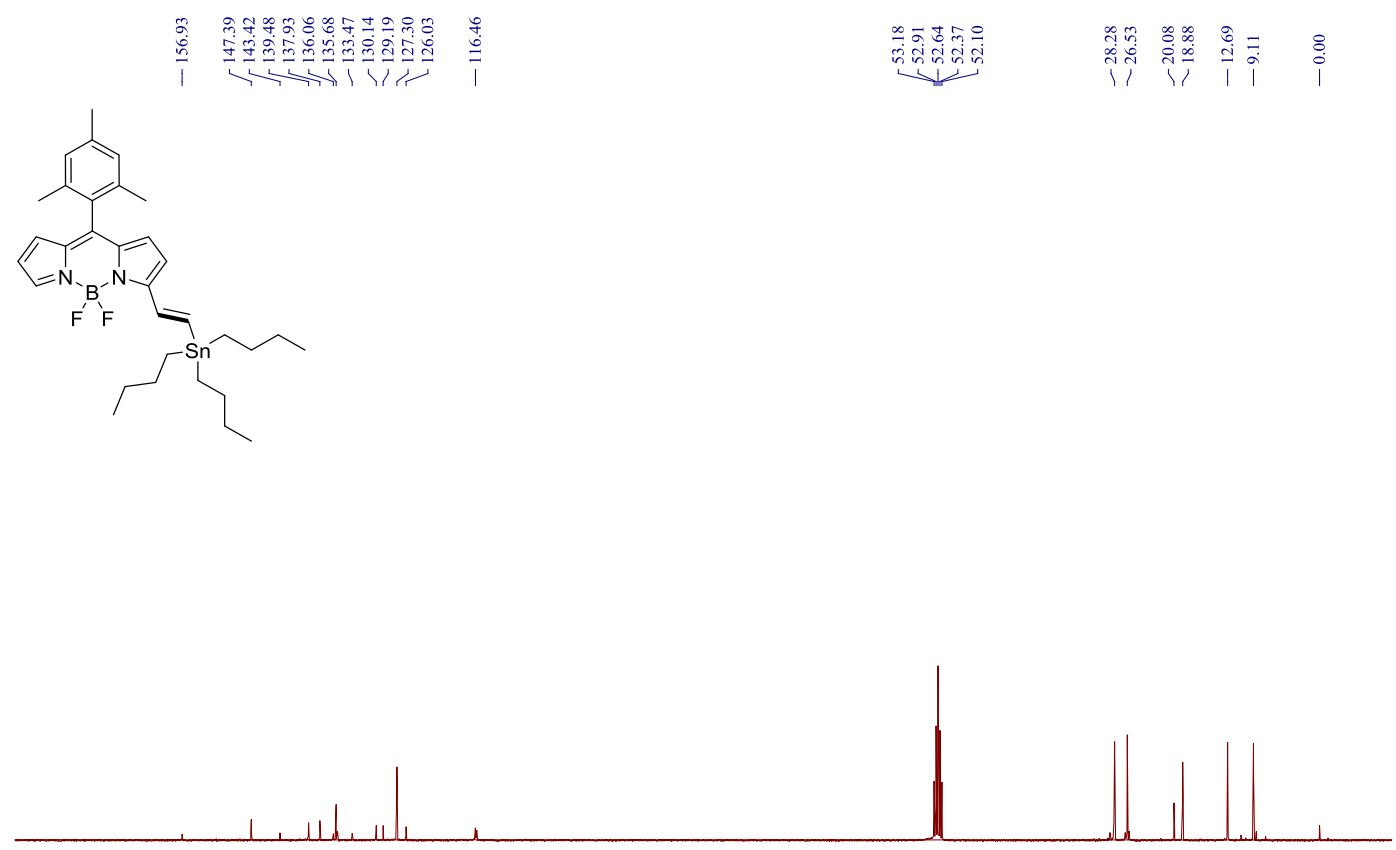

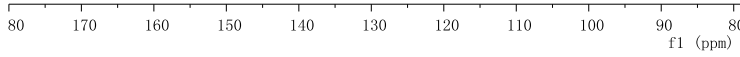

Figure S32. ${ }^{13} \mathrm{C}$ NMR (400 MHz) spectrum of $\mathbf{1 S n}$ in $\mathrm{CD}_{2} \mathrm{Cl}_{2}$. 

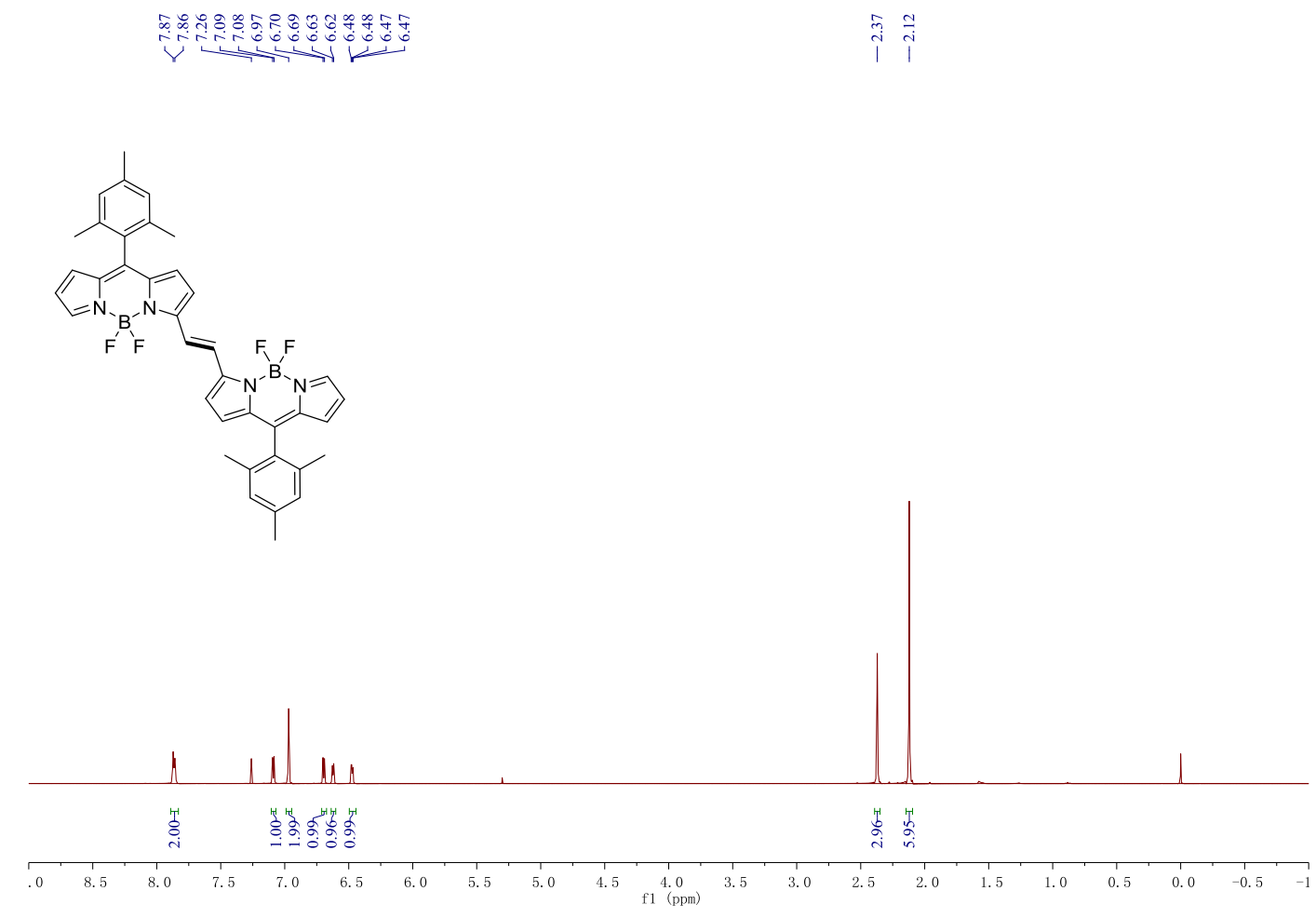

Figure S33. ${ }^{1} \mathrm{H}$ NMR (400 MHz) spectrum of 2 in $\mathrm{CDCl}_{3}$.
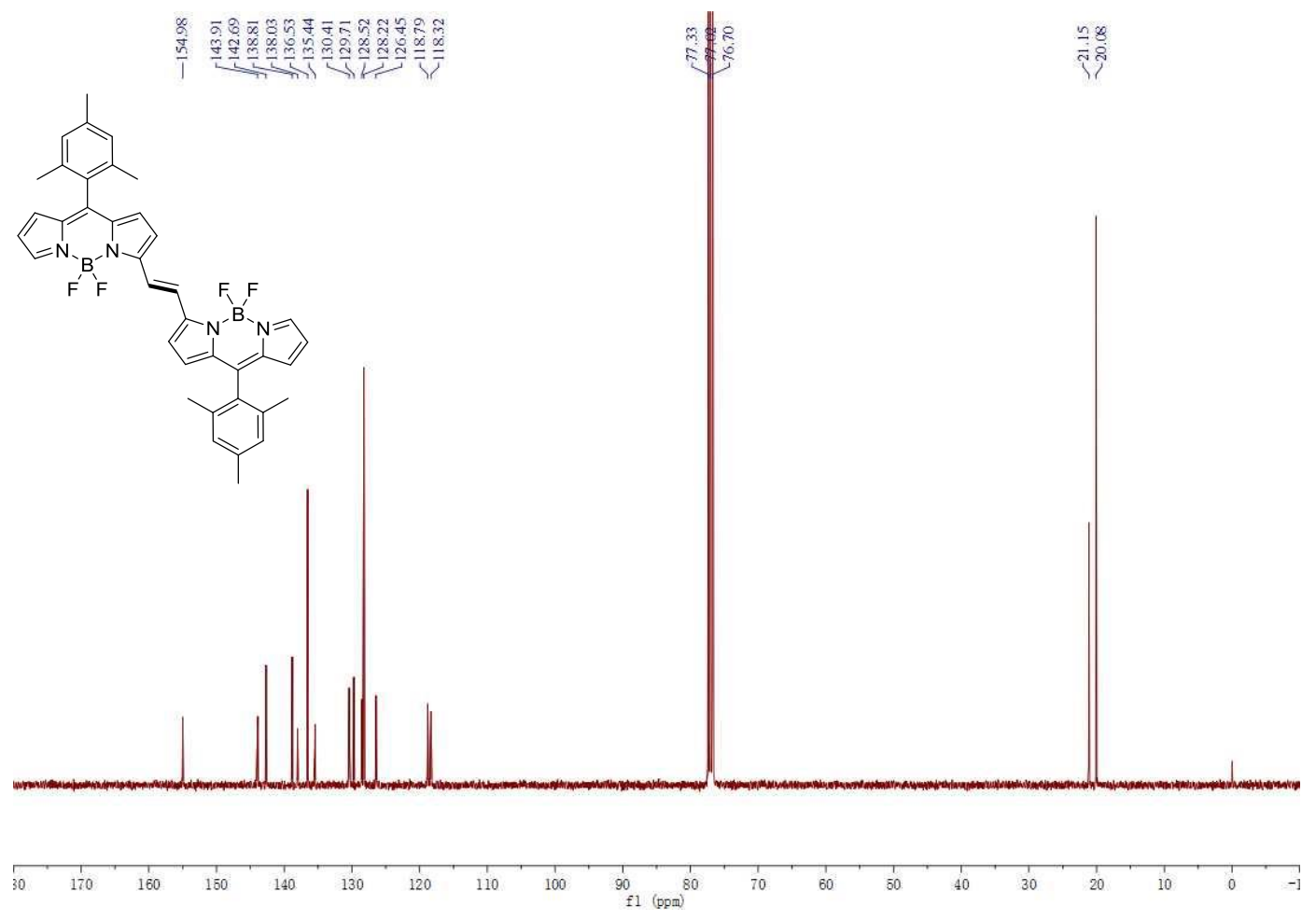

Figure S34. ${ }^{13} \mathrm{C}$ NMR (400 MHz) spectrum of 2 in $\mathrm{CDCl}_{3}$. 


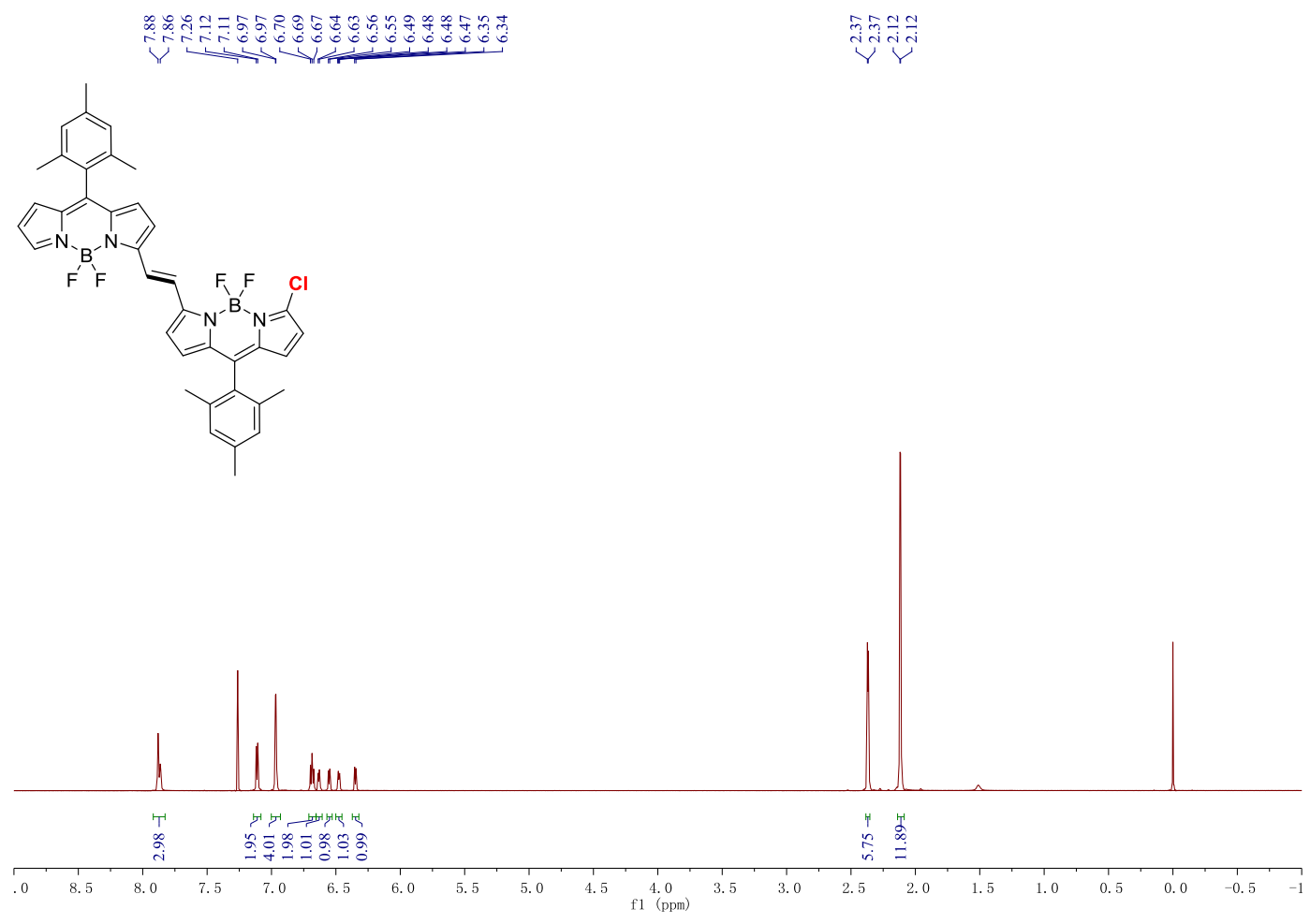

Figure S35. ${ }^{1} \mathrm{H}$ NMR (400 MHz) spectrum of $\mathbf{2 C l}$ in $\mathrm{CDCl}_{3}$.
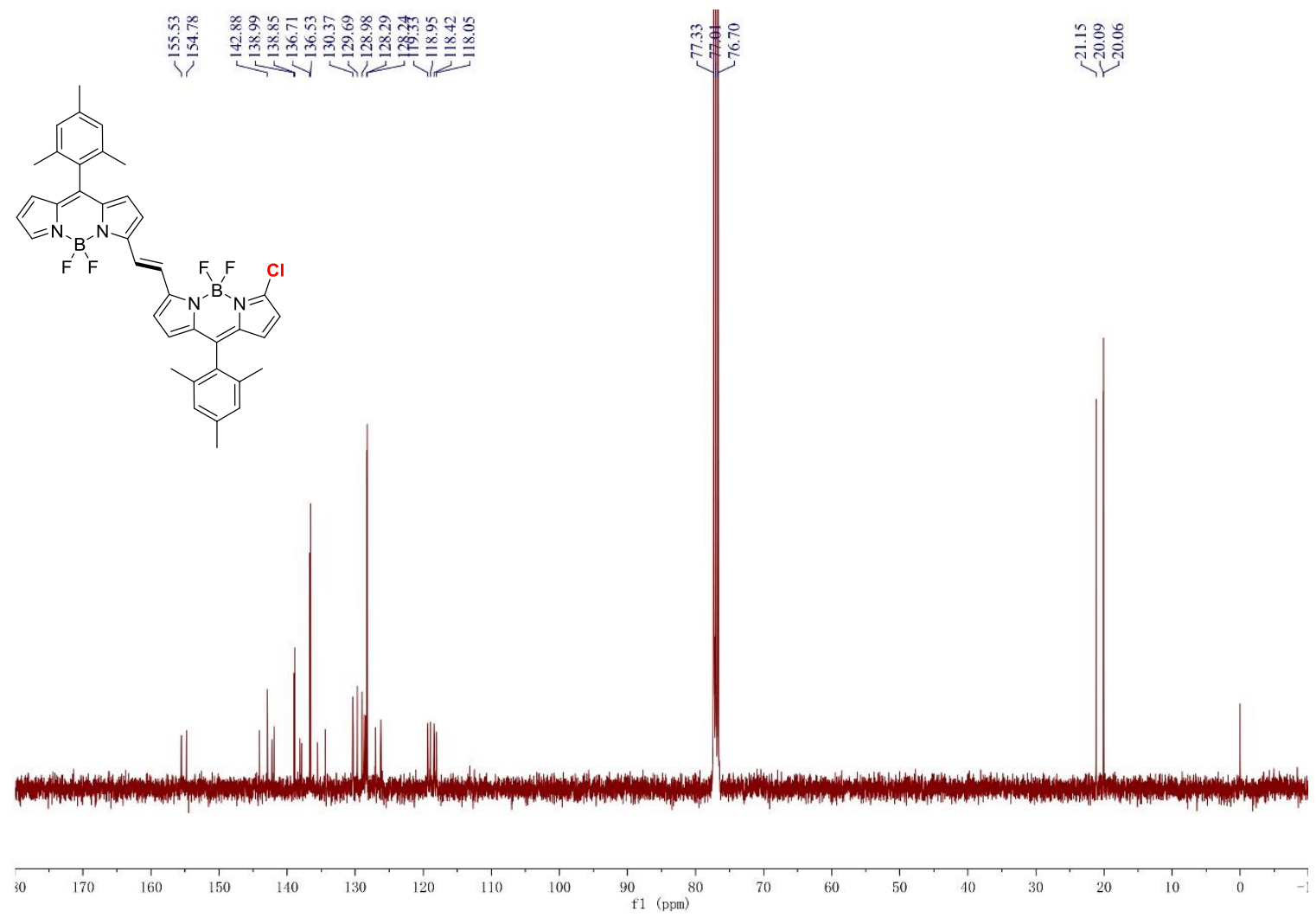

Figure S36. ${ }^{13} \mathrm{C}$ NMR (400 MHz) spectrum of $\mathbf{2 C l}$ in $\mathrm{CDCl}_{3}$. 


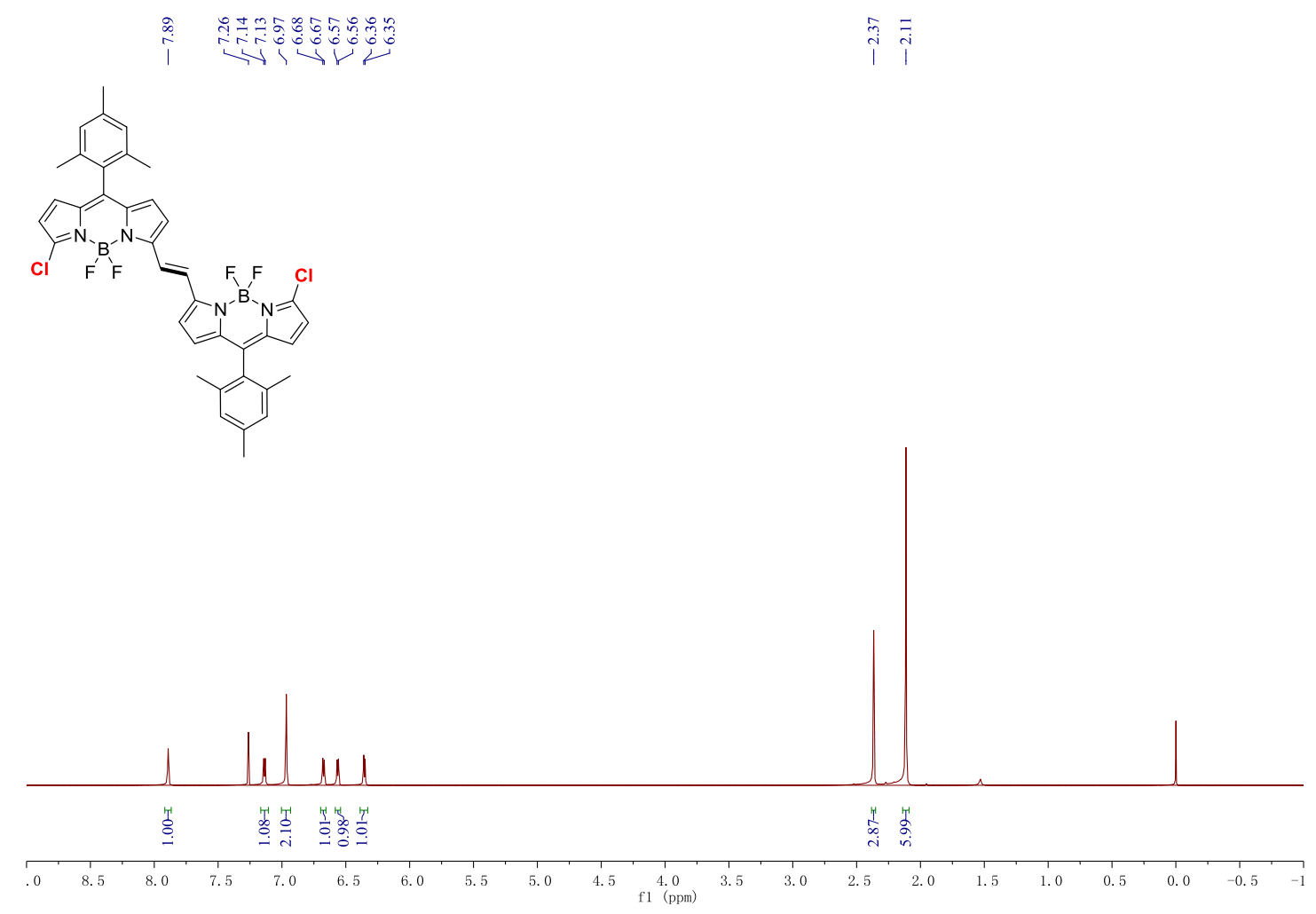

Figure S37. ${ }^{1} \mathrm{H}$ NMR (400 MHz) spectrum of $\mathbf{2} \mathbf{C l}_{2}$ in $\mathrm{CDCl}_{3}$.
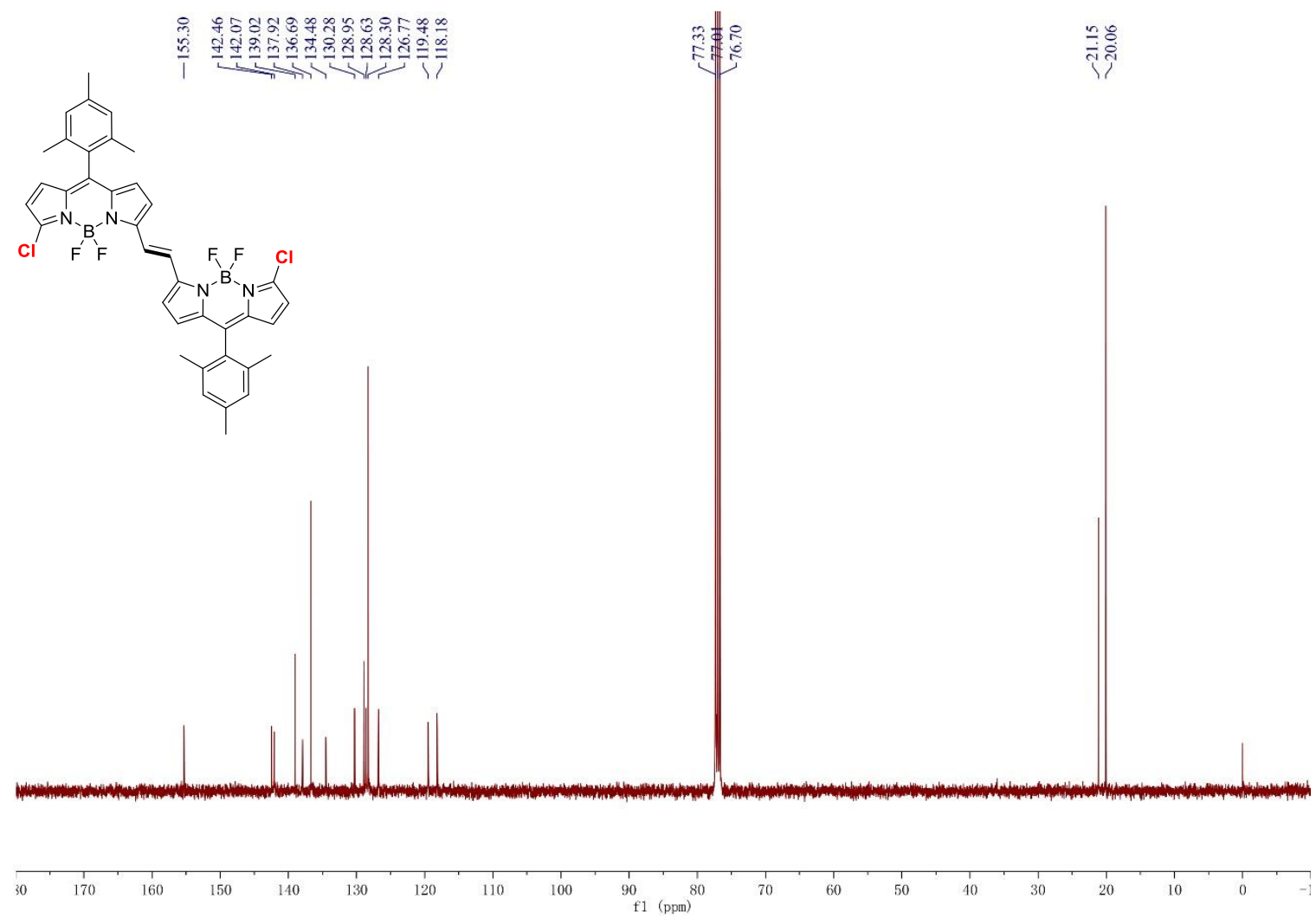

Figure S38. ${ }^{13} \mathrm{C}$ NMR (400 $\left.\mathrm{MHz}\right)$ spectrum of $\mathbf{2} \mathbf{C l}$ in $\mathrm{CDCl}_{3}$. 


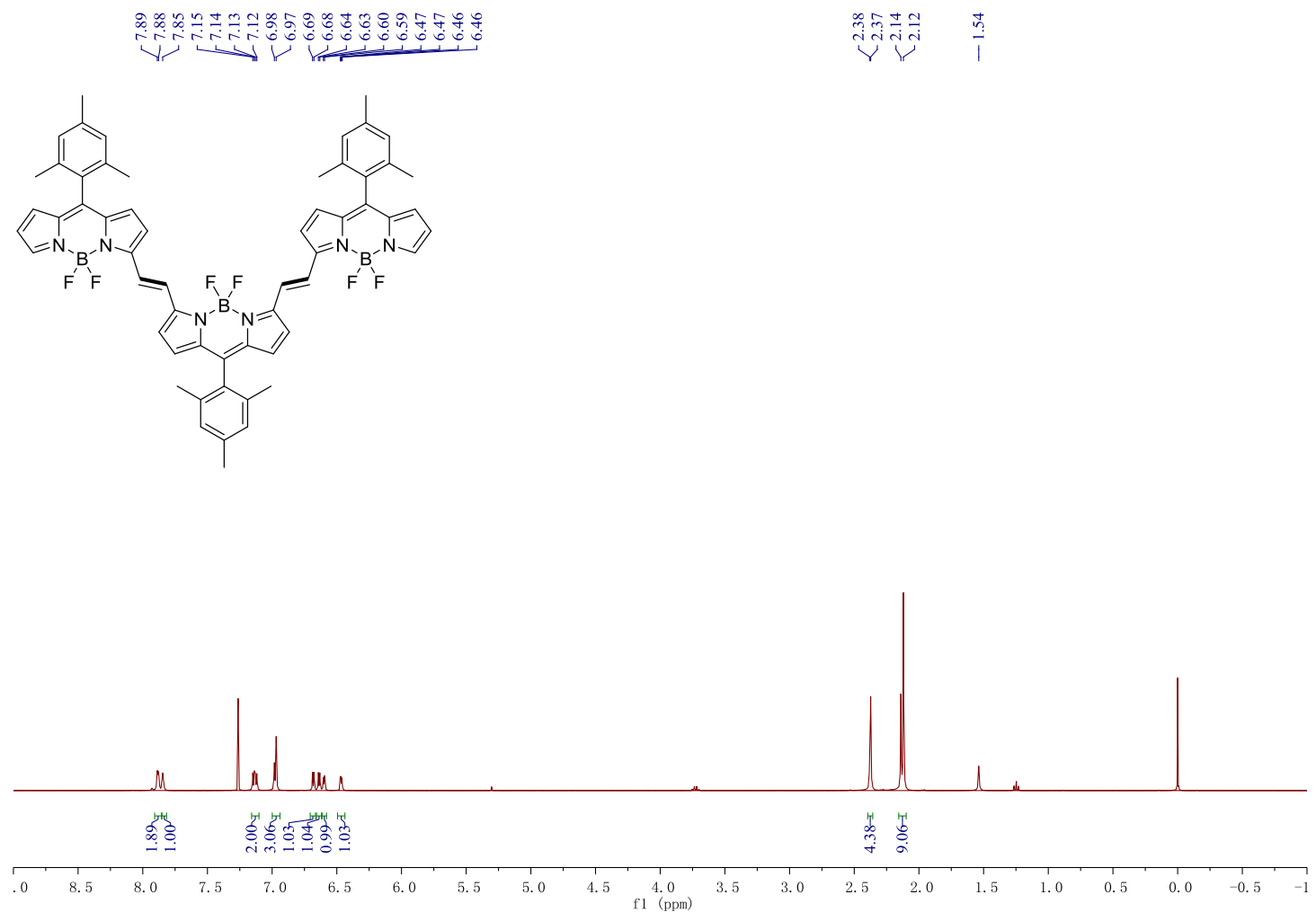

Figure S39. ${ }^{1} \mathrm{H}$ NMR (400 MHz) spectrum of 3 in $\mathrm{CDCl}_{3}$.
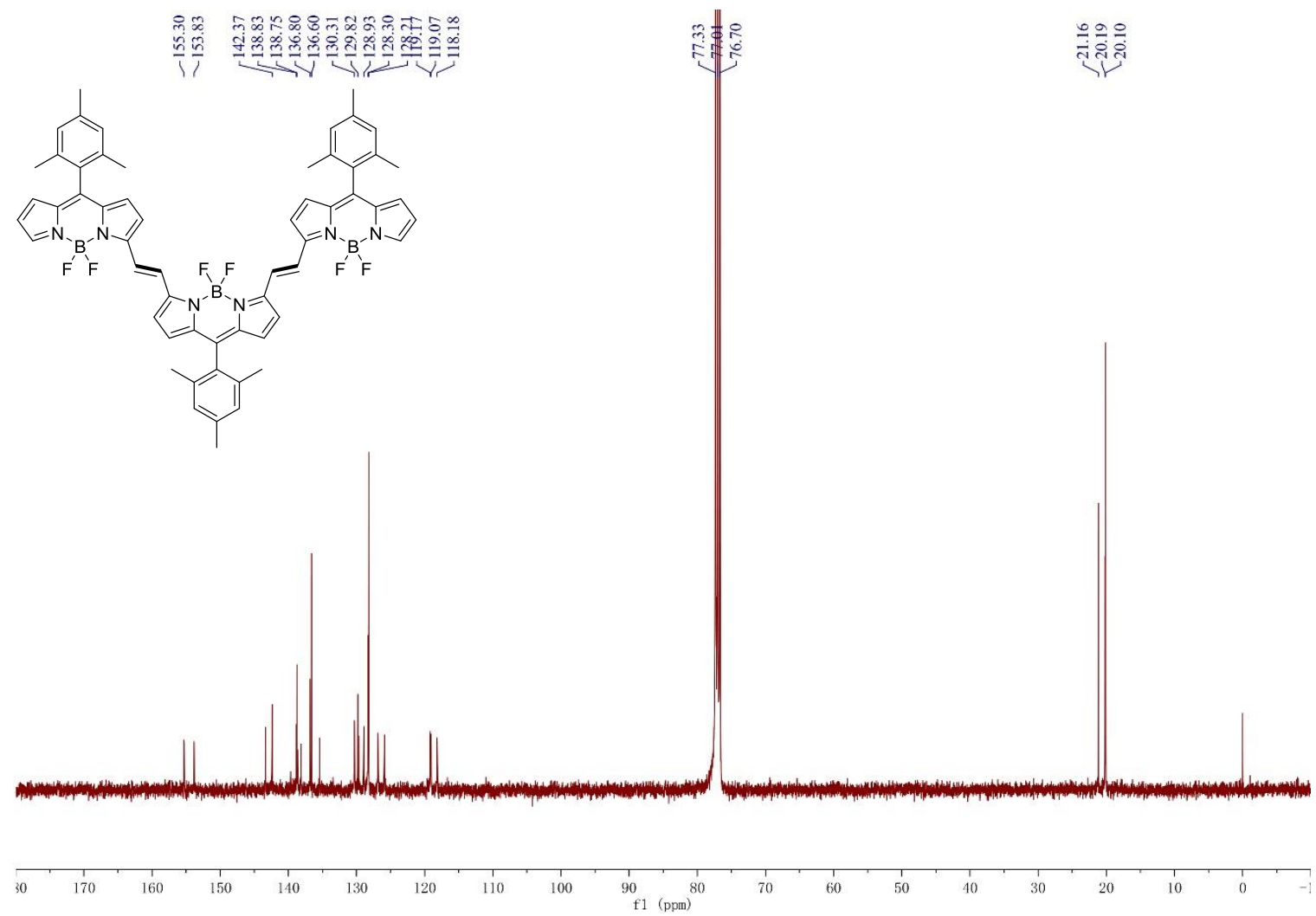

Figure S40. ${ }^{13} \mathrm{C}$ NMR (400 MHz) spectrum of 3 in $\mathrm{CDCl}_{3}$. 


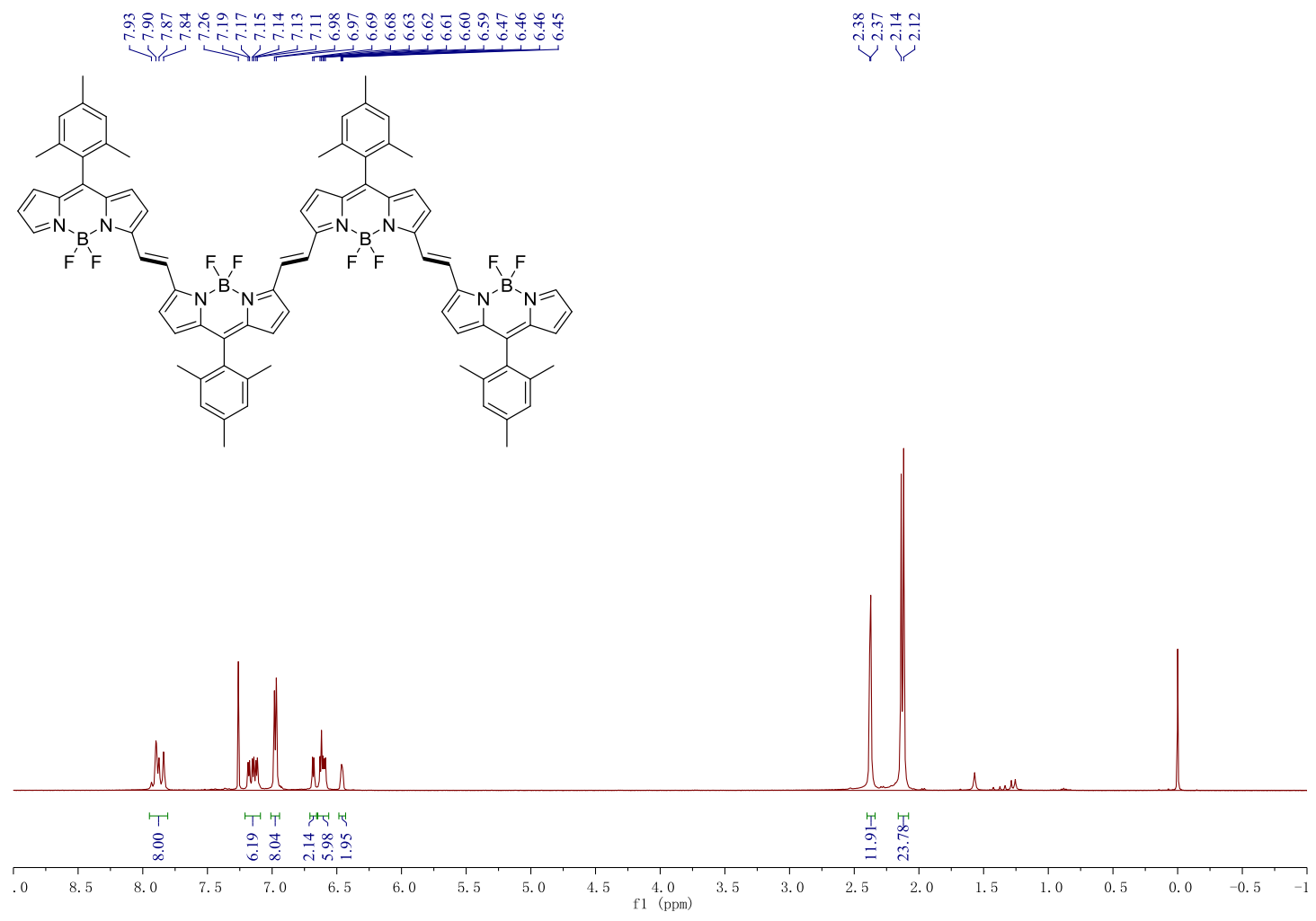

Figure S41. ${ }^{1} \mathrm{H}$ NMR (400 MHz) spectrum of 4 in $\mathrm{CDCl}_{3}$.

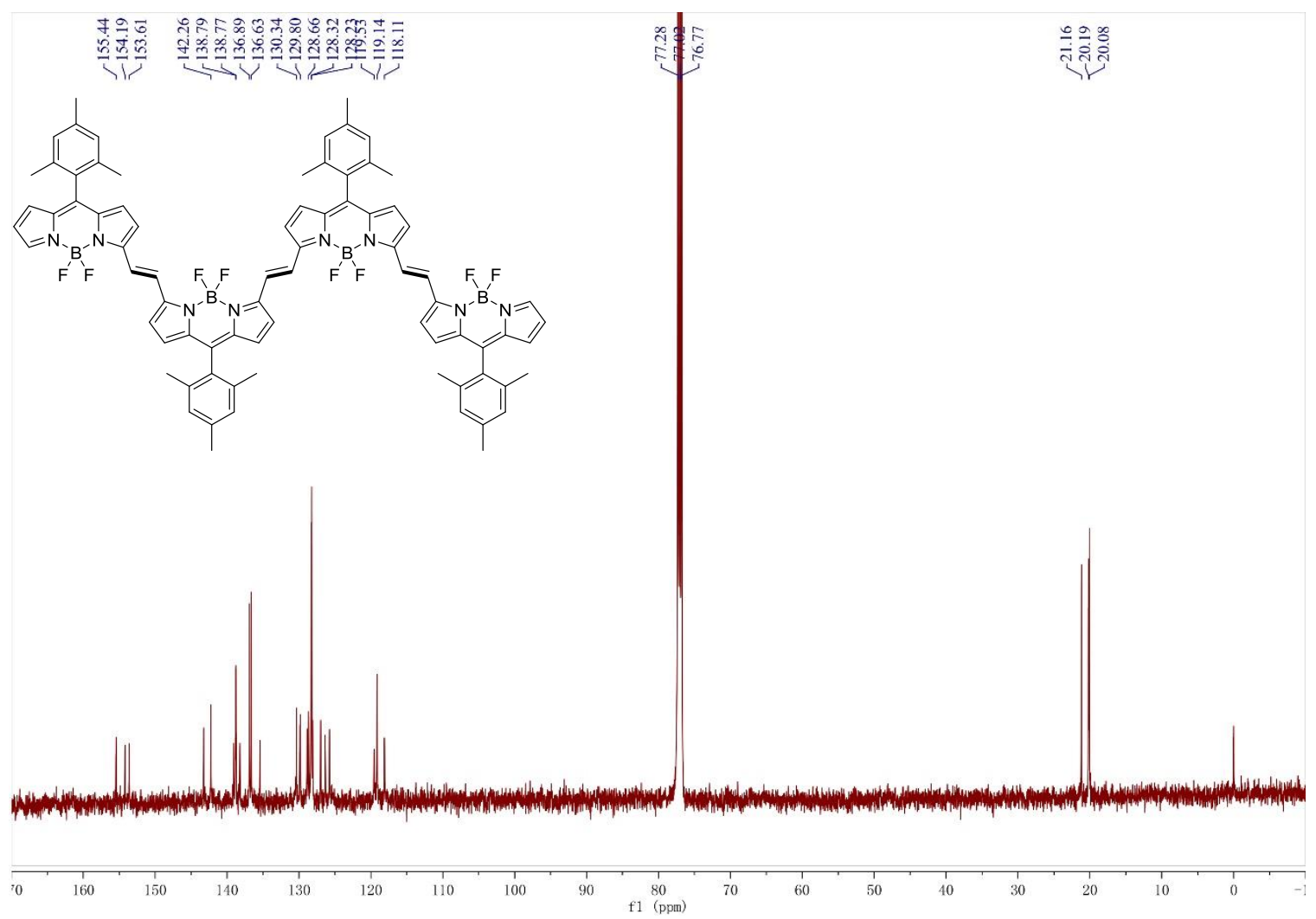

Figure S42. ${ }^{13} \mathrm{C}$ NMR (500 MHz) spectrum of 4 in $\mathrm{CDCl}_{3}$. 

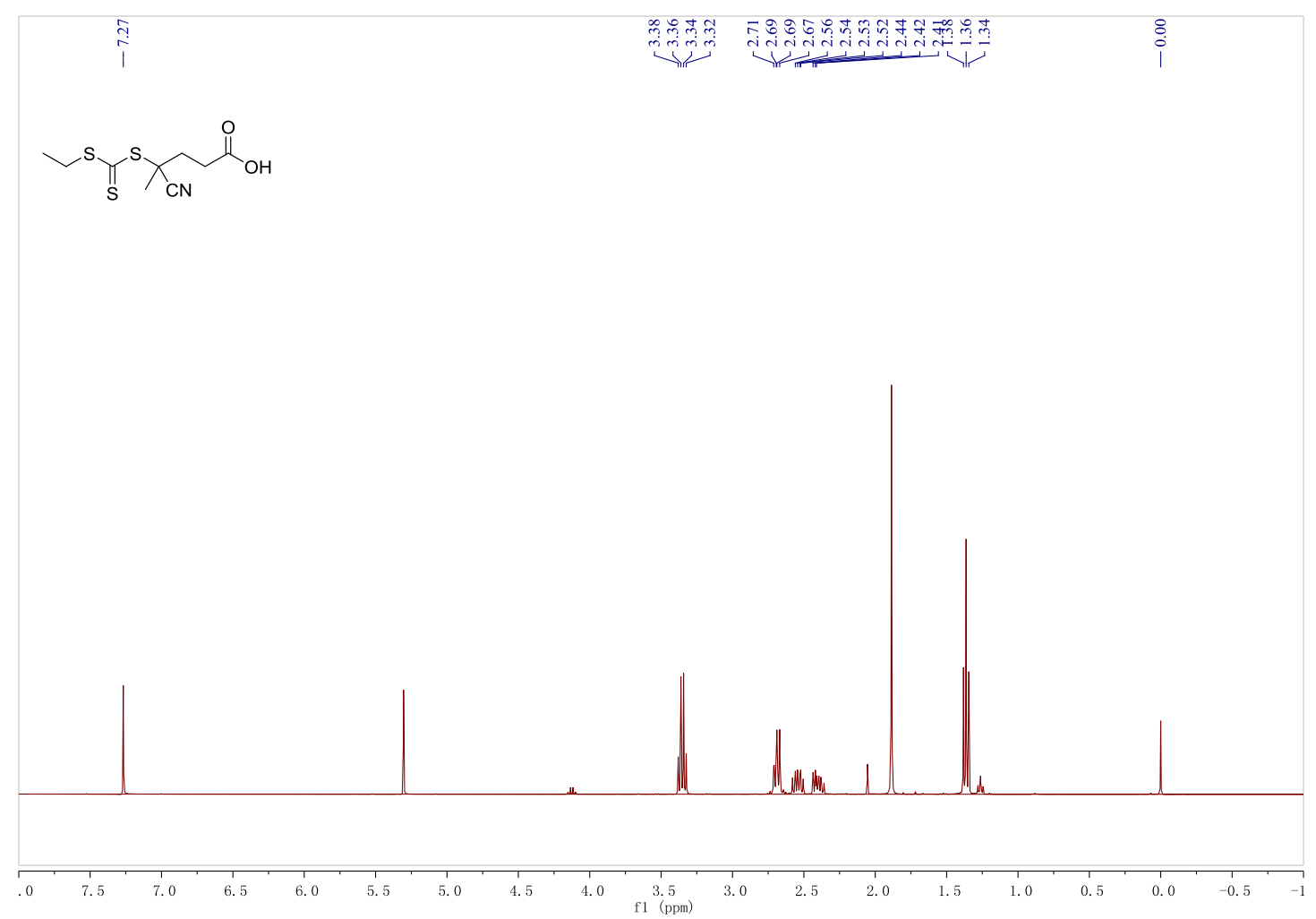

Figure S43. ${ }^{1} \mathrm{H}$ NMR (400 MHz) spectrum of CEPA in $\mathrm{CDCl}_{3}$.

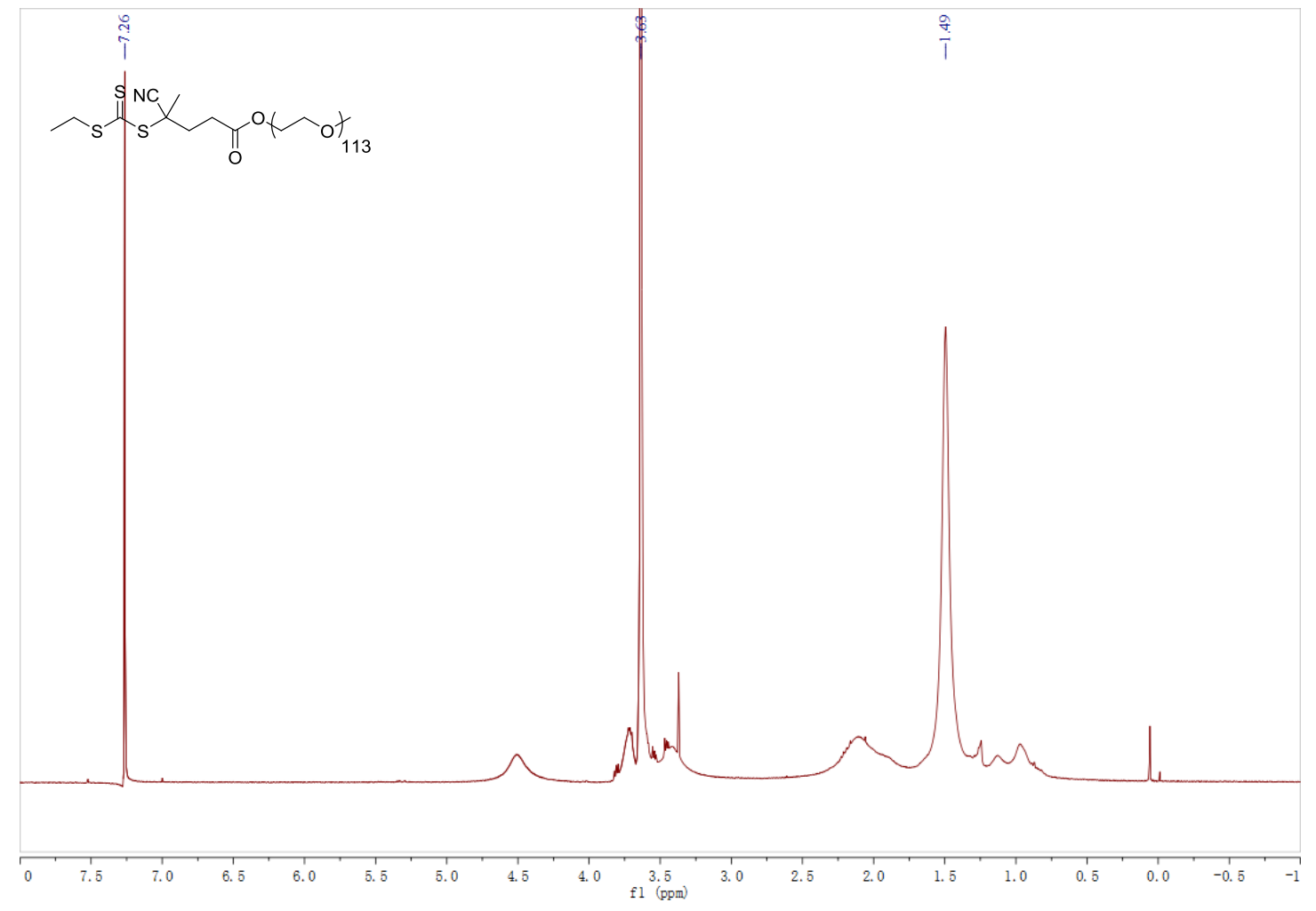

Figure S44. ${ }^{1} \mathrm{H}$ NMR (400 MHz) spectrum of PEG5000-CEPA in $\mathrm{CDCl}_{3}$. 


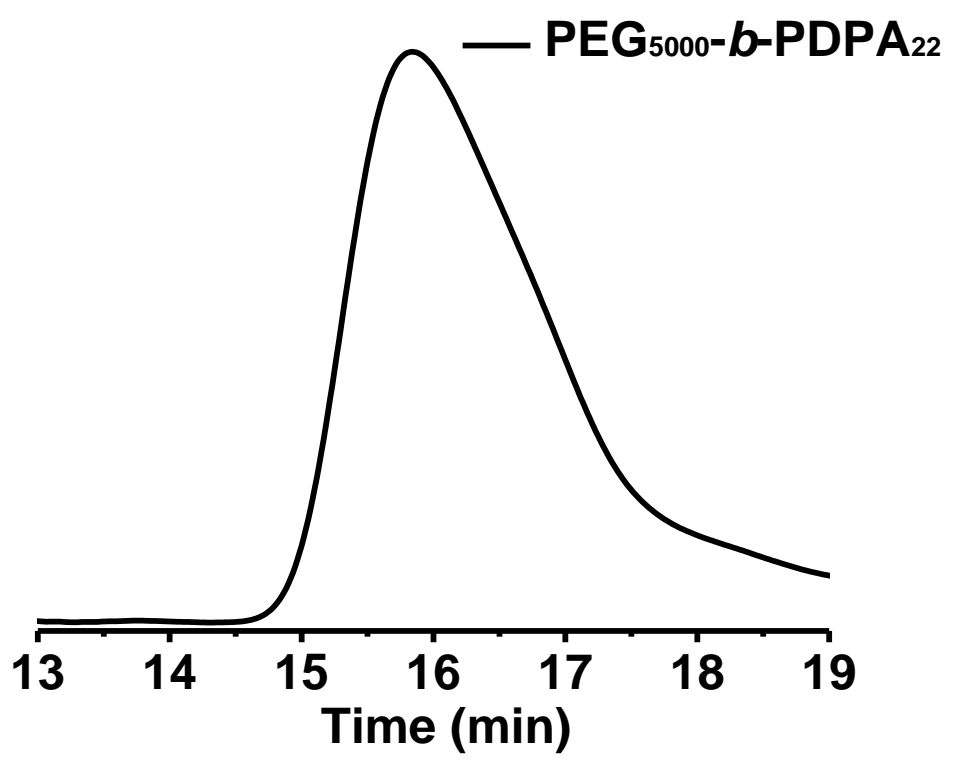

Figure S45. GPC spectrum of $\mathrm{PEG}_{5000}-b-\mathrm{PDPA}_{22}$. 


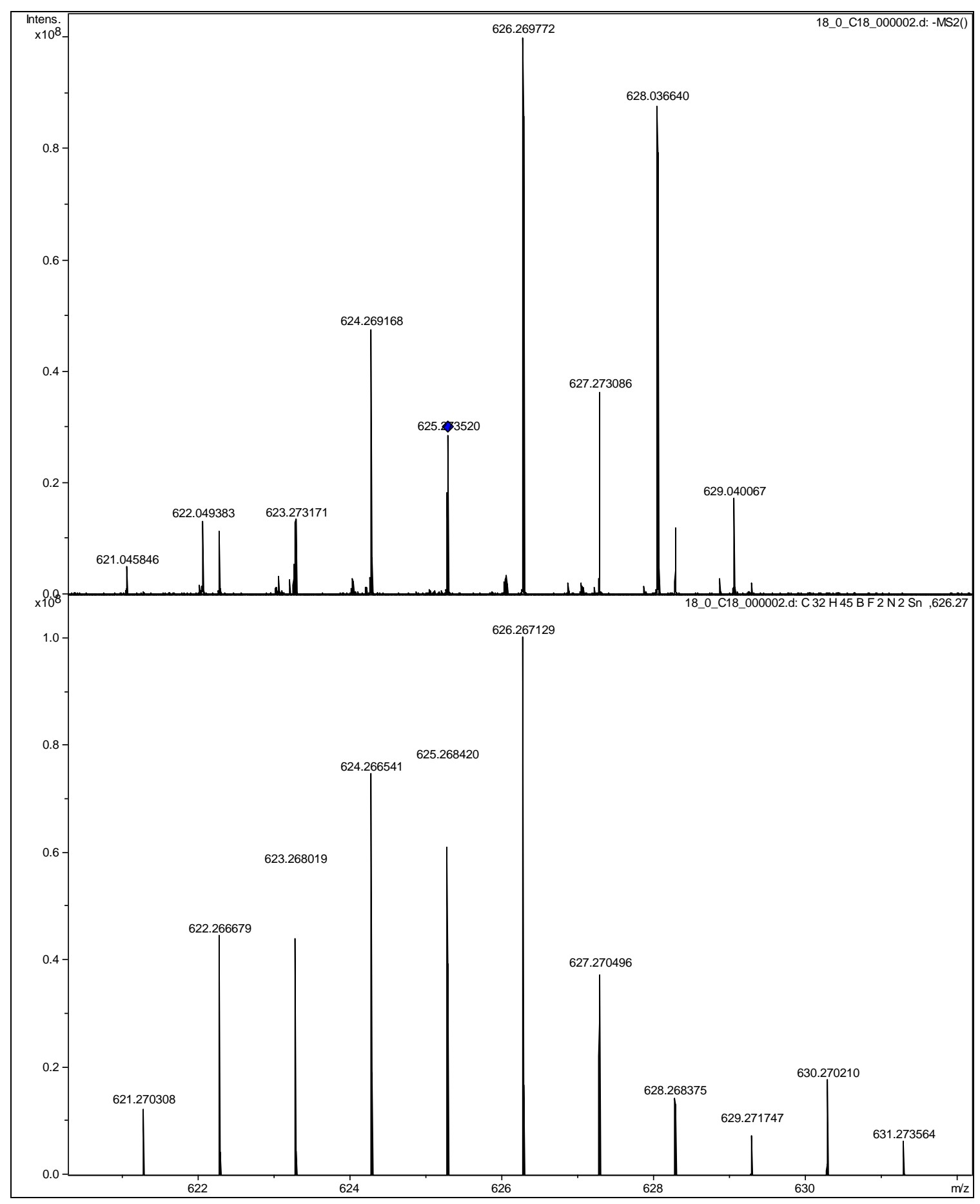

Figure S46. Obtained (top) and simulated (bottom) MALDI-TOF-MS spectrum of 1Sn. 


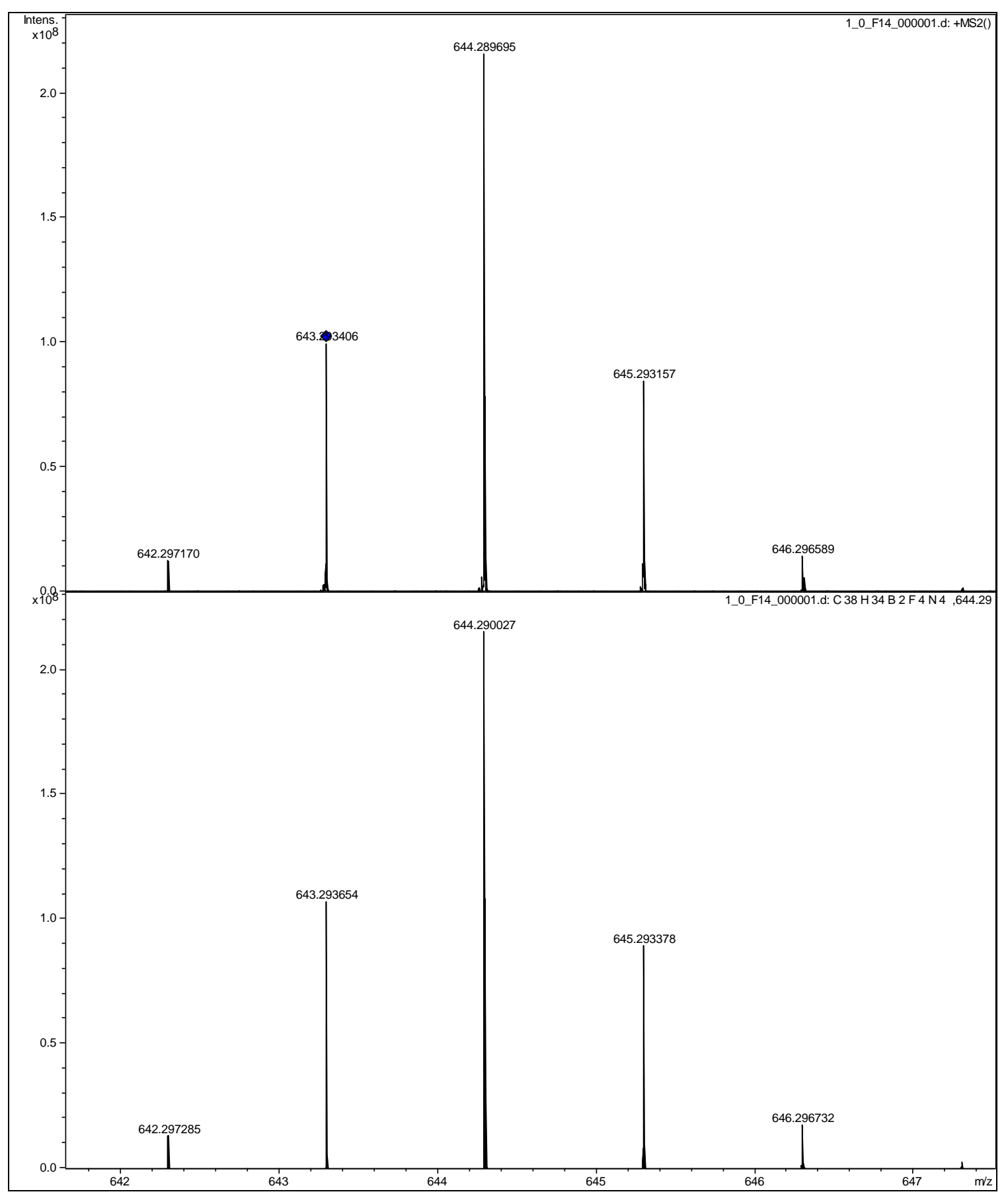

Figure S47. Obtained (top) and simulated (bottom) MALDI-TOF-MS spectrum of 2. 


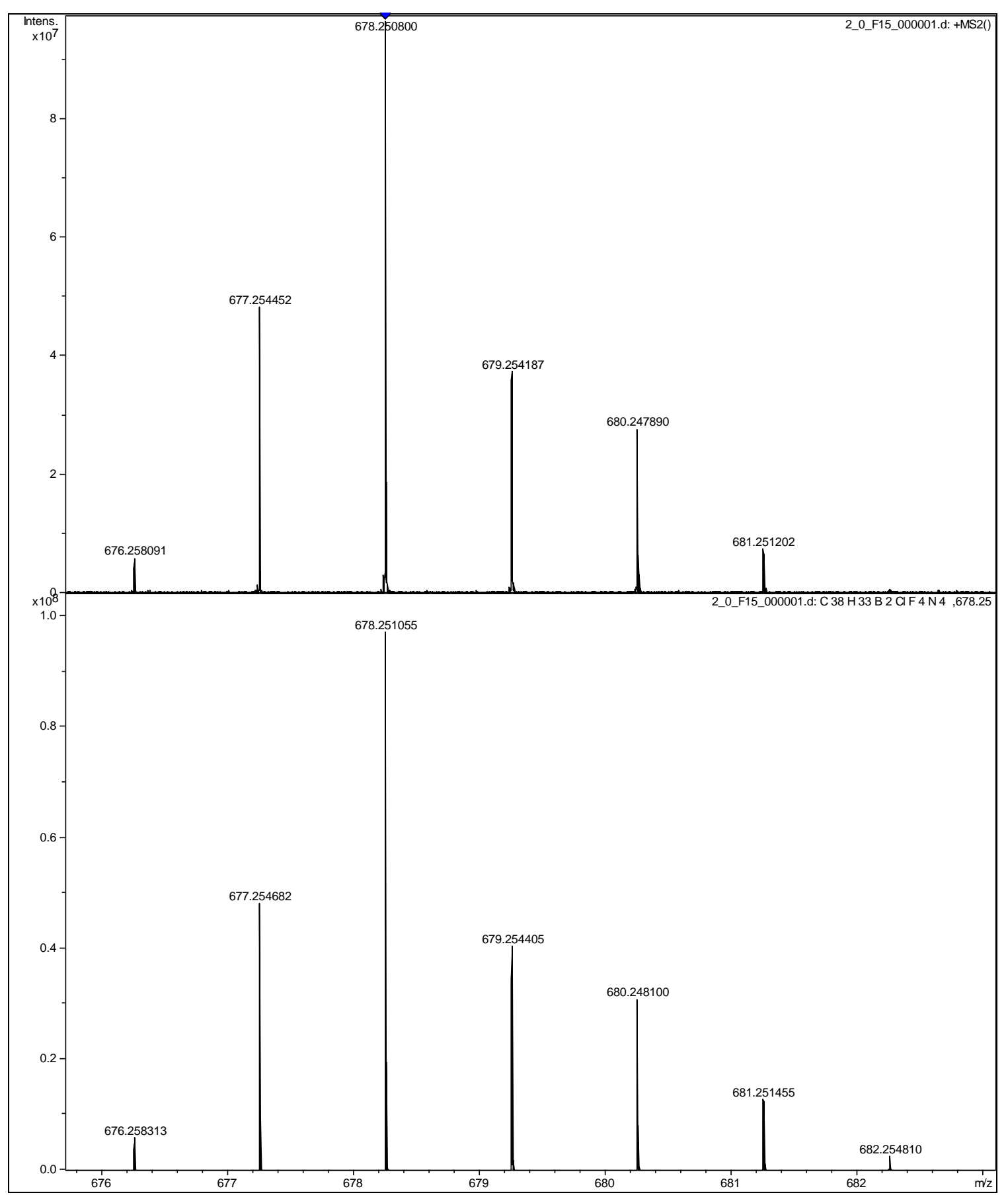

Figure S48. Obtained (top) and simulated (bottom) MALDI-TOF-MS spectrum of 2Cl. 


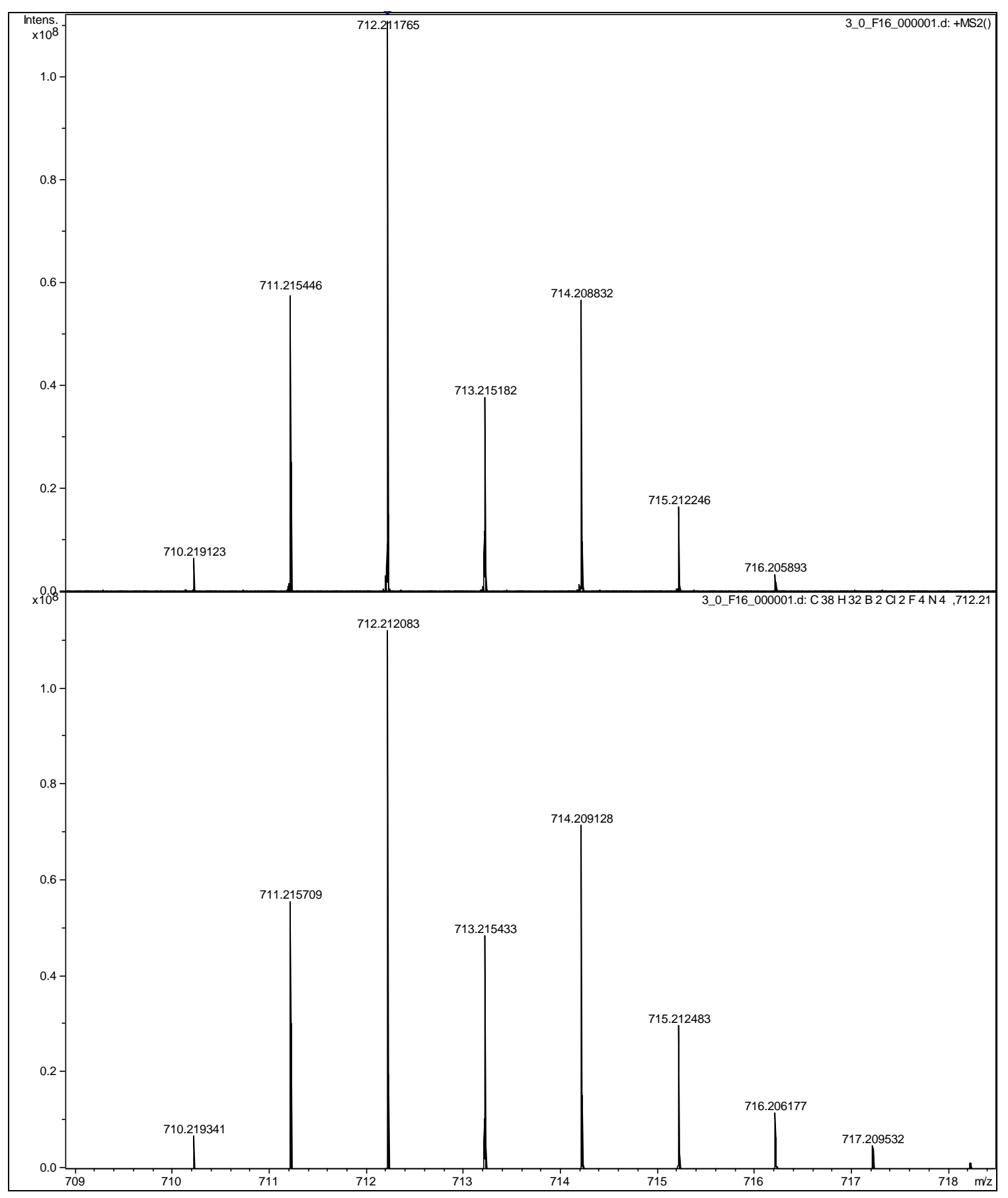

Figure S49. Obtained (top) and simulated (bottom) MALDI-TOF-MS spectrum of 2Cl2. 


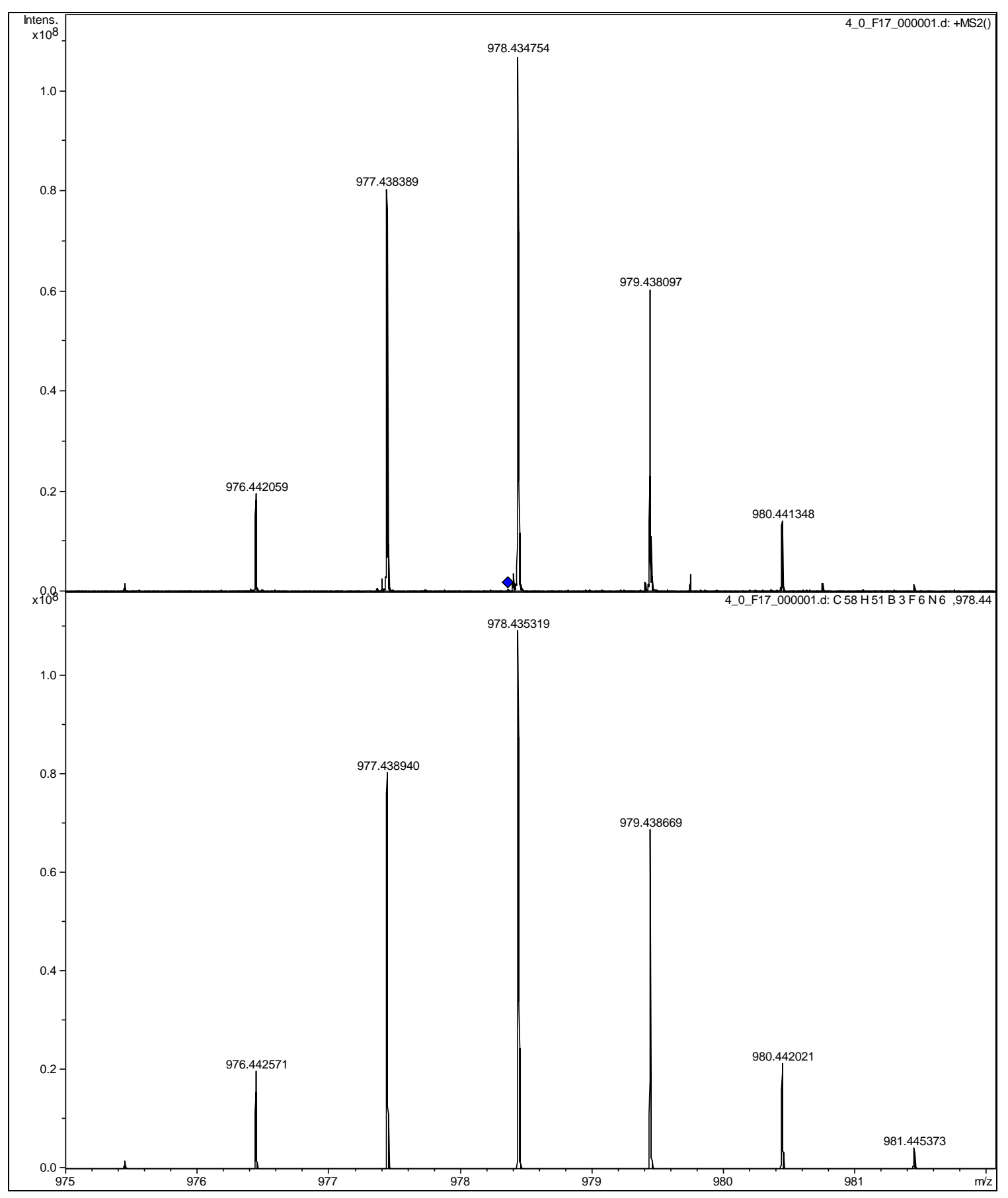

Figure S50. Obtained (top) and simulated (bottom) MALDI-TOF-MS spectrum of 3. 


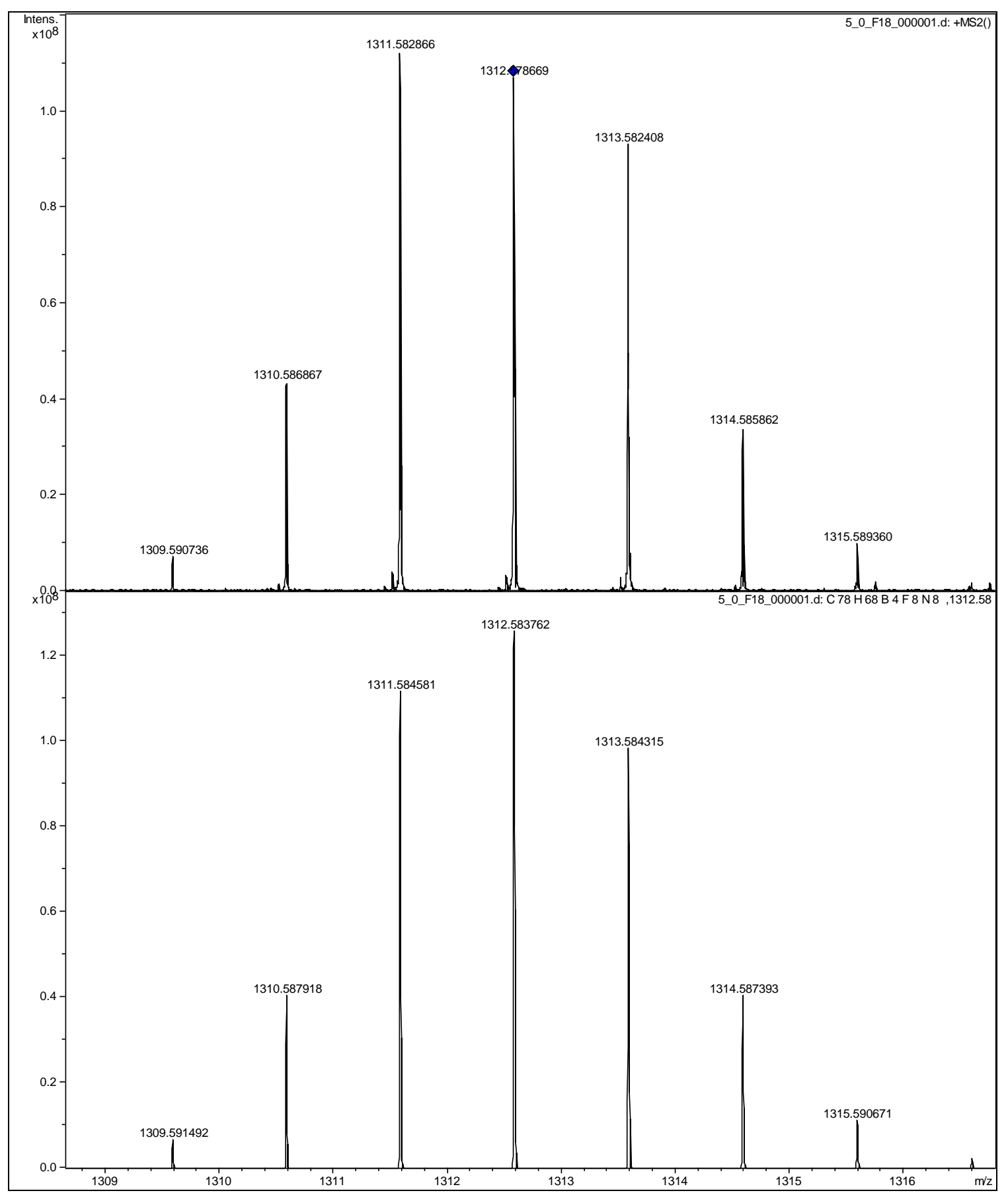

Figure S51. Obtained (top) and simulated (bottom) MALDI-TOF-MS spectrum of 4. 


\section{References:}

1. Isak, S. J.; Eyring, E. M. Fluorescence quantum yield of cresyl violet in methanol and water as a function of concentration. J. Phys. Chem. 1992, 96 (4), 1738.

2. Lei, Z.; Li, X.; Luo, X.; He, H.; Zheng, J.; Qian, X.; Yang, Y. Bright, Stable, and Biocompatible Organic Fluorophores Absorbing/Emitting in the Deep Near-Infrared Spectral Region. Angew. Chem. Int. Ed. 2017, 56 (11), 2979-2983.

3. (a) Benson, R. C.; Kues, H. A. Fluorescence properties of indocyanine green as related to angiography. Phys. Med. Biol., 1978, 23, 159. (b) Lakowicz, J. R. Principles of Fluorescence Spectroscopy, 3rd ed.; Springer: New York, 2006.

4. SAINT V 6.01 (NT) Software for the CCD Detector System, Bruker Analytical X-ray Systems, Madison, WI 1999.

5. Sheldrick, G. M. SHELXS-90, Program for the Solution of Crystal Structure, University of Göttingen, Germany, 1990.

6. Sheldrick, G. M. Acta Cryst. 2015, 71, 3-8.

7. SHELXTL 5.10 (PC/NT-Version), Program library for Structure Solution and Molecular Graphics, Bruker Analytical X-ray Systems, Madison, WI 1998.

8. (a) Gaussian 09, Revision D.01, M. J. Frisch, G. W. Trucks, H. B. Schlegel, G. E. Scuseria, M. A. Robb, J. R. Cheeseman, G. Scalmani, V. Barone, B. Mennucci, G. A. Petersson, H. Nakatsuji, M. Caricato, X. Li, H. P. Hratchian, A. F. Izmaylov, J. Bloino, G. Zheng, J. L. Sonnenberg, M. Hada, M. Ehara, K. Toyota, R. Fukuda, J. Hasegawa, M. Ishida, T. Nakajima, Y. Honda, O. Kitao, H. Nakai, T. Vreven, J. A. Montgomery, Jr., J. E. Peralta, F. Ogliaro, M. Bearpark, J. J. Heyd, E. Brothers, K. N. Kudin, V. N. Staroverov, T. Keith, R. Kobayashi, J. Normand, K. Raghavachari, A. Rendell, J. C. Burant, S. S. Iyengar, J. Tomasi, M. Cossi, N. Rega, J. M. Millam, M. Klene, J. E. Knox, J. B. Cross, V. Bakken, C. Adamo, J. Jaramillo, R. Gomperts, R. E. Stratmann, O. Yazyev, A. J. Austin, R. Cammi, C. Pomelli, J. W. Ochterski, R. L. Martin, K. Morokuma, V. G. Zakrzewski, G. A. Voth, P. Salvador, J. J. Dannenberg, S. Dapprich, A. D. Daniels, O. Farkas, J. B. Foresman, J. V. Ortiz, J. Cioslowski, and D. J. Fox, Gaussian, Inc., Wallingford CT, 2013; (b) Rinkevicius, Z., Tunell, I., Sałek, P., Vahtras, O., Ågren, H. J. Chem. Phys. 2003, 119, 34-46; (c) Helgaker, T., Jørgensen, P., Olsen, J., Ruud, K., Andersen, T., Bak, KL., Bakken, V., Christiansen, O., Dahle, P., Dalskov, EK., Enevoldsen, T., Heiberg, H., Hettema, H., Jonsson, D., Kirpekar, S., Kobayashi, R., Koch, H., Mikkelsen, KV., Norman, P., Packer, MJ., Saue, T., Taylor, PR., Vahtras, O., Jensen, HJA., Ågren, H. Dalton, an Ab Initio Electronic Structure Program, 1.0. 1997; (d) Koseki, S., Schmidt, M., Gordon, M. J. Phys. Chem. 1990, 96, 10678. 